\title{
Efetividade da Política Macroprudencial: um Exercício com Base no Buffer Contracíclico
}

\section{The Effectiveness of Macroprudential Policy: an Exercise Based on the Countercyclical Buffer}

\author{
Vinicius Ratton Brandi ${ }^{\mathrm{a}}$ \\ Joaquim Pinto de Andrade
}

\begin{abstract}
Resumo: Um dos elementos desestabilizadores da crise financeira internacional de 2008 foi a amplificação de choques financeiros. A tendência natural dos agentes se comportarem de forma procíclica foi reforçada por meio de outros canais. Dessa forma, as medidas macroprudenciais ganharam maior destaque na busca pela estabilidade financeira. Este trabalho traz contribuições que buscam esclarecer os efeitos de determinados instrumentos de regulação macroprudencial sobre variáveis macroeconômicas e financeiras, com base em um modelo que introduz fricções na oferta de crédito em um arcabouço DSGE novo-keynesiano, estimado para a economia brasileira. Os resultados sugerem uma maior adequação do instrumento de política macroprudencial contracíclico no caso de choques que se originam no próprio sistema financeiro e choques de política monetária. No caso dos choques de oferta e de demanda, a utilização do instrumento prudencial revela, na maioria das vezes, papel conflitante aos objetivos da autoridade monetária e resultado não conclusivo a respeito dos benefícios sobre a estabilidade financeira. Na comparação entre os diferentes conceitos de ciclo econômico, observa-se que uma maior cooperação da autoridade prudencial em relação aos objetivos da política monetária é proporcionada quando se utiliza a relação entre crédito e produto como referência para o acompanhamento do ciclo econômico.
\end{abstract}

Palavras-chave: DSGE. Políticas macroprudenciais. Regulação financeira.

\begin{abstract}
The international financial crisis of 2008 has made clear that the academic debate should incorporate financial frictions to investigate business cycle fluctuations and allocative efficiency. At the financial regulation side, macroprudential measures have gained a growing importance as an instrument in the search for financial stability. The main objective of this thesis consists in the evaluation of the role of specific macroprudential policies within a new keynesian model incorporating a financial system with frictions and adjustment costs estimated with Brazilian data. Parameters are estimated based on bayesian methods and time series from the Brazilian economy. As a relatively new literature, the debate is more populated by questions and challenges than by conclusive answers. In this broad debate, this work aims to contribute for the understand-

a Banco Central do Brasil. Superintendência de Seguros Privados.

b Universidade de Brasília (UnB), Faculdade de Economia, Administração e Contabilidade (FACE), Departamento de Economia. Brasília, DF, Brasil.
\end{abstract}


ing of the effects of some macroprudential policy instruments over relevant macroeconomic and financial variables. In what concerns specifically the countercyclical capital buffer, the analysis is extended to evaluate its contributions to the objectives pursued by the prudenctial authority and, also, its coordination with monetary authority ones.

Keywords: DSGE. Macroprudential policy. Financial regulation.

JEL Classification: E5; E6; G2.

\section{Introdução}

Um dos elementos mais desestabilizadores da crise financeira internacional de 2008 foi a amplificação de choques financeiros ao longo da economia. A tendência natural dos agentes se comportarem de forma procíclica foi reforçada por diversos canais, incluindo os padrões contábeis, as práticas de chamadas de margem e os movimentos de alavancagem e desalavancagem tanto das instituições financeiras quanto de empresas e consumidores. Com base nesse aprendizado, o Comitê de Basileia divulgou novo arcabouço regulatório, conhecido por Basileia III (BASEL COMMITTEE ON BANKING SUPERVISION, 2010, 2011), voltado para aprimorar as regras de requerimento de capital e para incorporar regras de gestão do risco de liquidez nas instituições bancárias. Com isso, as medidas macroprudenciais ganharam destaque ainda maior na busca das autoridades de regulação e supervisão bancária pela estabilidade financeira.

Ao estabelecerem a necessidade de colateral e capital próprio para a obtenção de empréstimos, os modelos baseados nas abordagens originais de Bernanke, Gertler e Gilchrist (1999) e Kiyotaki e Moore (1997) descrevem as condições determinadas pelo contrato de empréstimo para representar fricções restritas ao lado da demanda por empréstimos. Mais recentemente, no entanto, os estudos de Meh e Moran (2010), Gerali, Neri, Sessa e Signoretti (2010), Gertler e Karadi (2011) e Basel Committee on Banking Supervision (2012) têm buscado incorporar fricções do lado da oferta de crédito, relacionadas normalmente ao grau de competitividade da indústria, restrições no capital bancário, estratégias de atuação no mercado e solidez.

Esse novo arcabouço permite, entre outros aspectos, a incorporação de políticas macroprudenciais impondo restrições à atuação dos bancos, bem como a análise de seus efeitos sobre o ciclo econômico e sua interação com a política monetária. Se, por um lado, as políticas macroprudenciais alteram as condições na oferta de crédito e produzem efeito sobre o mecanismo de transmissão da política monetária representado pelo canal de crédito, a política monetária tem seus efeitos sobre os preços dos ativos e sobre o montante de crédito da economia, indicadores-chave na avaliação da estabilidade financeira. 
Nessa literatura, o setor financeiro é definido usualmente com base em um acelerador financeiro em que o instrumento de capital, cuja dinâmica é influenciada por variações reais no volume de crédito da economia, tem o papel de encarecer o custo dos empréstimos ao setor produtivo. Em geral, as conclusões apontam para a importância de se diferenciar a natureza dos choques que influenciam as condições de crédito e os preços dos ativos. Embora a política macroprudencial tenha o papel de contribuir no combate a uma deterioração nas condições financeiras, sugere-se que, no caso de um choque de produtividade, a política macroprudencial torna-se ineficaz (ANGELINI; NERI; PANETTA, 2011; BEAU; CLERC; MOJON, 2011; KANNAN; RABANAL; SCOTT, 2009; RESENDE; DIB; PEREVALOV, 2010; ANGELONI; FAIA (2009).

No caso brasileiro, Carvalho e Castro (2016) encontram evidências de que a falta de coordenação entre as políticas macroprudencial e monetária produz efeitos prejudiciais à ancoragem das expectativas inflacionárias. Ainda, com base em um modelo dinâmico estocástico de equilíbrio geral (DSGE) adaptado para as características da economia brasileira, sugerem que a combinação de políticas convencionais de recolhimento compulsório, requerimento de capital e monetária é capaz de gerar resultados equivalentes aos proporcionados por outros instrumentos de política macroprudencial. O trabalho de Carvalho e Castro (2017) investiga a interação da política fiscal com as demais políticas monetária e macroprudencial e encontra uma combinação ótima de políticas na qual a política monetária reage a variações na inflação e a macroprudencial, a variações no hiato de crédito, ambas de forma contracíclica.

Nesse contexto, o presente artigo busca contribuir para as discussões envolvendo os efeitos de políticas relacionados às regras de liquidez e de requerimento de capital contracíclico sobre a flutuação econômica. Com base em um modelo novo-keynesiano estimado com dados da economia brasileira, investigam-se os impactos da utilização do requerimento de capital contracíclico sobre determinadas variáveis macroeconômicas e discutem-se seus efeitos sobre os objetivos regulatórios tanto da autoridade prudencial quanto da autoridade monetária. ${ }^{1}$

Os resultados sugerem sua maior adequação no caso da economia experimentar choques que se originam no próprio sistema financeiro ou choques de política monetária. No caso dos choques de oferta ou de demanda, a utilização do instrumento prudencial revelou, na maioria das vezes, papel conflitante aos objetivos da autoridade monetária e resultado não conclusivo a respeito dos benefícios sobre a estabilidade financeira. Percebe-se, ainda, que uma maior cooperação da autoridade prudencial em relação aos objetivos da política monetária é proporcio-

$1 \quad$ Vide Pinheiro et al. (2015) para maiores detalhes sobre a implementação do Acordo de Basileia III no Brasil. 
nada quando se utiliza a relação entre crédito e produto como referência para o acompanhamento do ciclo econômico.

Este artigo está organizado da seguinte forma: a segunda seção apresenta as principais características do modelo; a terceira descreve sua estimação e suas propriedades; a quarta aborda a avaliação das políticas macroprudenciais; e, por fim, a quinta traz as considerações finais do trabalho.

\section{Modelo}

Esta seção apresenta uma descrição resumida do modelo analítico de Gerali, Neri, Sessa e Signoretti (2010) contendo uma extensão para incorporar uma regra de requerimento de capital apurada com base nos ativos ponderados pelo risco, conforme padrões internacionais de regulação. Permite-se, dessa forma, que os fatores de ponderação de risco desenvolvam uma dinâmica de modo a introduzir os efeitos pró-cíclicos do sistema financeiro sobre a economia real. Além disso, os ativos dos bancos passam a incluir ativos de alta liquidez em montante proporcional ao volume de depósitos, os quais representam instrumentos de renda fixa que podem ser convertidos em reservas bancárias em prazo curto.

O modelo original introduz fricções financeiras e outros fatores que permitem avaliar o papel da oferta de crédito sobre as flutuações econômicas em um arcabouço DSGE com rigidez nominal à la Rotemberg (1982). As famílias consomem, trabalham e acumulam bens imobiliários num mercado com oferta fixa, maximizando sua utilidade esperada com base na relação entre o consumo presente e o consumo defasado multiplicado por um coeficiente de hábito, na quantidade do bem imobiliário e nas horas trabalhadas.

Supõe-se que as famílias pacientes possuem um fator de desconto intertemporal maior do que o fator atribuído às famílias impacientes e aos empreendedores, de maneira que as famílias pacientes representem os agentes superavitários responsáveis pela oferta de recursos ao sistema financeiro. Dessa maneira, as famílias pacientes poupam e efetuam depósitos bancários remunerados. Além disso, são proprietárias das firmas produtoras do bem final e dos bancos, recebendo remuneração com base no pagamento de dividendos.

Esse fluxo financeiro é intermediado pelos bancos, em que as famílias impacientes tomam empréstimos a juros, sujeitas a uma restrição de crédito determinada por uma fração do valor esperado do colateral oferecido pelas famílias impacientes, o bem imobiliário, representando ineficiências exógenas na oferta de crédito.

Ainda, as famílias oferecem tipos de trabalho diferenciados aos sindicatos, que vendem a força de trabalho a empacotadores de mão de obra perfeitamente competitivos que reúnem a força de trabalho diferenciada em um pacote de tra- 
balho homogêneo e com elasticidade de substituição constante, a ser ofertado aos empreendedores.

Os empreendedores, por seu turno, contratam o trabalho das famílias e compram capital dos produtores de capital para produzir bens intermediários homogêneos em um mercado de competição perfeita, de acordo com determinada tecnologia. A oferta de crédito aos empreendedores é limitada pelo valor esperado do capital um período à frente, que serve como colateral nas operações de empréstimos, e por um fator estocástico responsável por representar fricções financeiras no mercado de crédito. Esses mesmos agentes também são os proprietários das firmas produtoras de capital, que atuam em um mercado de competição perfeita adquirindo o capital depreciado do período anterior e investindo certa quantidade do bem final para produzir capital novo a ser utilizado na tecnologia de produção aos empreendedores.

Os bens finais da economia são produzidos em um mercado de competição monopolística e de preços rígidos, no qual as firmas adquirem o bem intermediário dos empreendedores e apenas incorporam a marca para produzir o bem final, num processo de diferenciação que não envolve custos adicionais. Os preços são indexados a uma combinação entre a inflação passada e a inflação de estado estacionário. Para fixar preços distintos desse indexador, a firma deve incorrer em um custo de ajustamento quadrático.

Embora a estrutura do modelo omita características específicas da economia brasileira, entende-se que sua utilização já permita identificar mecanismos e relações relevantes para a análise aqui proposta. No que tange à participação do crédito imobiliário no sistema financeiro, ainda que o mercado brasileiro apresente volumes proporcionalmente inferiores aos observados em economias mais desenvolvidas, configura-se como segmento relevante no segmento de pessoas físicas. Numa leitura mais ampla, também os imóveis descritos no modelo podem ser interpretados como o total de bens duráveis financiados, abrangendo os empréstimos colateralizados presentes na economia, como destacam Quint e Rabanal (2014).

Apresentamos, a seguir, maiores detalhes sobre os aspectos de intermediação financeira. Os bancos atuam em um ambiente de competição monopolística, em que seu poder de mercado permite a imposição de markdowns e markups em suas operações passivas e ativas, respectivamente, sobre a taxa definida pela política monetária, baseada em uma regra de Taylor convencional, com grau de persistência elevado e indexada pelo desvio da inflação observada em relação à meta e pela variação do produto. Cada banco é composto por uma matriz, responsável pela gestão do capital bancário, e por duas filiais, uma responsável por captar depósitos das famílias pacientes e outra por realizar operações de empréstimos às famílias impacientes e aos empreendedores. 
O capital bancário é considerado praticamente fixo no curto prazo. Sua dinâmica é definida de forma bastante simples, na qual o capital é depreciado por uma determinada taxa $\delta_{b}$ e pode ser acumulado apenas com base na retenção dos lucros do período anterior $J_{\text {t-1 }}^{b}$. Em termos reais, tem-se:

$$
\pi K_{t}^{b}=\left(1-\delta_{b}\right) K_{t-1}^{b}+J_{t-1}^{b}
$$

Aqui, busca-se uma inovação à equação patrimonial original de Gerali, Neri, Sessa e Signoretti (2010) de modo a incorporar a necessidade de manutenção de ativos de alta liquidez compatíveis com o passivo de curto prazo da instituição. Como nesse modelo os contratos são celebrados e encerrados a cada período, não apresentando, portanto, uma estrutura a termo de taxas e fluxos de caixa, a quantidade de ativos de alta liquidez é definida como proporção dos depósitos.

Dessa forma, os bancos devem obedecer à seguinte restrição patrimonial, na qual seus ativos, representados pelos ativos de alta liquidez $L C R_{t}$ e pelos empréstimos às famílias impacientes e firmas $B_{t}$, devem ser financiados pelo capital próprio $K_{t}^{b}$ e pelos depósitos efetuados pelas famílias pacientes $D_{t}$ :

$$
B_{t}+L C R_{t}=K_{t}^{b}+D_{t}
$$

onde

$$
L C R_{t}=\tau_{t}^{L C R} D_{t}
$$

na quais $\tau_{t}^{L C R}$ representa a parcela dos depósitos a serem mantidos em ativos de alta liquidez.

Ainda, seguindo a abordagem proposta por Angelini, Enria, Neri, Panetta e Quagliariello (2010), o requerimento de capital bancário é apurado com base nos ativos ponderados pelo risco, tal como determina o padrão regulatório internacional, e não apenas com base no valor de seus ativos. Dessa maneira, o custo de ajustamento do capital bancário passa a ser definido pela equação 4:

$$
\frac{k_{K_{b}}}{2}\left(\frac{K_{t}^{b}}{\omega_{t} B_{t}}-v^{b}\right) K_{t}^{b}
$$

em que $w_{t}$ representa o fator de ponderação de risco dos empréstimos concedidos às famílias e aos empreendedores, $\kappa_{\mathrm{kb}}$ consiste no parâmetro relativo ao custo de ajustamento do capital bancário e $v^{b}$ é o parâmetro que define a relação ótima de capital bancário, definida de forma exógena. 
Fixando-se os valores de $w_{t}$, obtém-se estrutura semelhante à do Acordo de Basileia I, no qual os fatores de ponderação ao risco são insensíveis a variações no risco. Uma forma de incorporar a sensibilidade ao risco na determinação desses fatores consiste em permitir que seus valores possuam uma dinâmica condicional a variações em determinada variável macroeconômica $X_{t}$, como demonstrado na equação 5:

$$
\mathrm{w}_{t}=\left(1-\rho_{\omega}\right) \omega+\left(1-\rho_{\omega}\right) \chi_{\omega}\left(\log X_{t}-\log X_{t-4}\right)+\rho_{\omega} \mathrm{w}_{t-1}
$$

em que um parâmetro $\chi_{\omega}<0$ indica o comportamento pró-cíclico na apuração do capital regulatório.

Dessa forma, o problema do banco na gestão de sua estrutura de capital consiste em escolher o volume de empréstimos $B_{t}$ e de depósitos $D_{t}$ de forma a maximizar o valor presente esperado dos seus fluxos de caixa futuros, utilizando-se o fator estocástico de desconto apurado para as famílias pacientes $\Lambda_{0, t}^{P}$, seus proprietários:

$$
\begin{aligned}
& E_{0} \sum_{t=0}^{\infty} \Lambda_{0, t}^{p}\left[\left(1+R_{t}^{b}\right) B_{t}-B_{t+1} \pi_{t+1}+\left(1+R_{t}^{L C R}\right) L C R_{t}-L C R_{t+1} \pi_{t+1}+D_{t+1} \pi_{t+1}-\left(1+R_{t}^{d}\right) D_{t}\right. \\
& \left.+\left(K_{t+1}^{b} \pi_{t+1}-K_{t}^{b}\right)-\frac{k_{K_{b}}}{2}\left(\frac{K_{t}^{b}}{\omega_{t} B_{t}}-v^{b}\right)^{2} K_{t}^{b}\right]
\end{aligned}
$$

sujeito à restrição de balanço patrimonial (equação 2) e assumindo como dadas as taxas de juros da aplicação $R_{t}^{b}$ e captação $R_{t}^{d}$ das matrizes, bem como a taxa de remuneração dos ativos de elevada liquidez $R_{t}^{L C R}$. Substituindo-se essa restrição avaliada em $t$ e $t+1$ na função objetivo, obtém-se o problema da matriz de uma forma resumida:

$$
\max _{\left\{B_{t}, D_{t}\right\}}\left[R_{t}^{b} B_{t}+R_{t}^{L C R} L C R_{t}-R_{t}^{d} D_{t}-\frac{k_{K_{b}}}{2}\left(\frac{K_{t}^{b}}{\omega_{t} B_{t}}-v^{b}\right)^{2} K_{t}^{b}\right]
$$

Porém, como, pela equação patrimonial, tem-se:

$$
D_{t}=\frac{B_{t}-K_{t}^{b}}{1-\tau_{t}^{L C R}}
$$

A condição de primeira ordem de $B_{t}$, assumindo $K_{t}$ dado, oferece uma relação entre o spread nas operações da matriz e a relação entre seus ativos e capi- 
tal. Assumindo-se que os bancos possuem financiamento irrestrito à taxa utilizada como instrumento de política monetária $r_{t}$, por arbitragem, e que os ativos altamente líquidos são remunerados por taxa equivalente à de política monetária, $R_{t}^{L C R}$ $=r_{t}$, observa-se que a incorporação do instrumento voltado para a gestão do risco de liquidez de curto prazo não interfere na taxa da aplicação das matrizes.

Nesse caso, a equação os bancos igualam a receita marginal de um aumento nos empréstimos, representada pelo spread bancário, ao seu custo marginal, indicado pelo desvio sobre a relação ótima de capital, conforme demonstra a equação 9:

$$
R_{t}^{b}=r_{t}-\frac{k_{K_{b}}}{\omega_{t}}\left(\frac{K_{t}^{b}}{\omega_{t} B_{t}}-v^{b}\right)\left(\frac{K_{t}^{b}}{B_{t}}\right)^{2}
$$

Com relação às filais que se relacionam diretamente com as famílias e empreendedores, supõe-se que os contratos de depósito e empréstimo adquiridos pelas famílias e pelos empreendedores são compostos por uma cesta de produtos financeiros diferenciados contendo elasticidade de substituição constante e ofertados por cada filial bancária, num arcabouço à la Dixit-Stiglitz (1977) e Blanchard e Kiyotaki (1987). No caso dos empréstimos, os tomadores determinam o montante de empréstimos em cada banco de forma a minimizar o pagamento de juros, sujeito ao montante total de empréstimos demandado. No caso dos depósitos, a demanda por depósitos é definida com base na maximização dos juros recebidos no depósito para um dado montante.

Os bancos atuam num setor com competição monopolística e fixam as taxas de remuneração dos depósitos e dos empréstimos de forma a maximizarem seus lucros e, assim, acumularem capital bancário, supondo um custo de ajustamento quadrático de forma a incorporar evidências sobre a rigidez das taxas no mercado bancário.

\section{Estimação e Propriedades do Modelo}

A base de dados é composta por 11 séries temporais contendo 41 observações trimestrais no período compreendido entre o primeiro trimestre de 2002 e o primeiro trimestre de 2012. A seguir, apresenta-se o detalhamento de cada uma dessas séries:
a) consumo: consumo real das famílias, dessazonalizado (IBGE, Sistema de Contas Nacionais);
b) investimento: formação bruta de capital fixo, em termos reais, dessazona- lizado (IBGE, Sistema de Contas Nacionais);
c) salários: rendimento médio nominal do trabalho principal, dessazonali- zado (IBGE, Pesquisa Mensal de Emprego); 
d) inflação: Índice Nacional de Preços ao Consumidor Amplo (IPCA) (IBGE);

e) taxa de juros nominal: Taxa Selic (BCB);

f) taxa dos empréstimos às famílias: taxa referencial (TR) $+12 \%$ a.a. (BCB);

g) taxa dos empréstimos às firmas: média entre as taxas das operações de aquisições de bens e as taxas dos empréstimos concedidos pelo Banco Nacional de Desenvolvimento Econômico e Social (BNDES) com prazo superior a 48 meses, ponderadas por seus respectivos volumes $(\mathrm{BCBe}$ BNDES);

h) taxas dos depósitos: taxa de captação média de operações com pessoa física no Sistema Financeiro Nacional (BCB);

i) empréstimos às famílias: volume de financiamento imobiliário (BCB);

j) empréstimos às firmas: volume de empréstimos a pessoas jurídicas com recursos domésticos livres, excluídas as operações de conta garantida, somado ao volume de empréstimos concedidos pelo BNDES (BCB);

k) depósitos: depósitos a prazo, de poupança e outros realizados em instituições bancárias (BCB).

Em comparação com as séries utilizadas em Gerali, Neri, Sessa e Signoretti (2010), excluiu-se a série de preços dos imóveis em função da dificuldade na obtenção dos dados relativos ao mercado doméstico e, também, pela pouca relevância de algumas proxies elaboradas a partir de informação obtida junto a determinadas instituições. De fato, a inclusão dessas séries pouco contribuía para uma melhor identificação dos parâmetros no processo de estimação. ${ }^{2}$ As séries que apresentaram tendência foram tratadas para se tornarem estacionárias com base no filtro HP (HODRICK; PRESCOTT, 1997), utilizando-se o parâmetro de suavização $\lambda$ equivalente a 1.600. As demais séries, de inflação e de salários, foram subtraídas das suas médias. A Figura 1 apresenta as variáveis transformadas.

2 Dada a ausência de informações relativas às taxas praticadas no segmento imobiliário, utilizou-se a TR como referência para as variações na taxa dos empréstimos às famílias, com a finalidade de minimamente capturar as oscilações observadas nas taxas de juros de curto prazo. Cabe destacar, no entanto, que a inclusão da série pouco contribui para a identificação dos parâmetros do modelo. 
Figura 1 - Base de dados
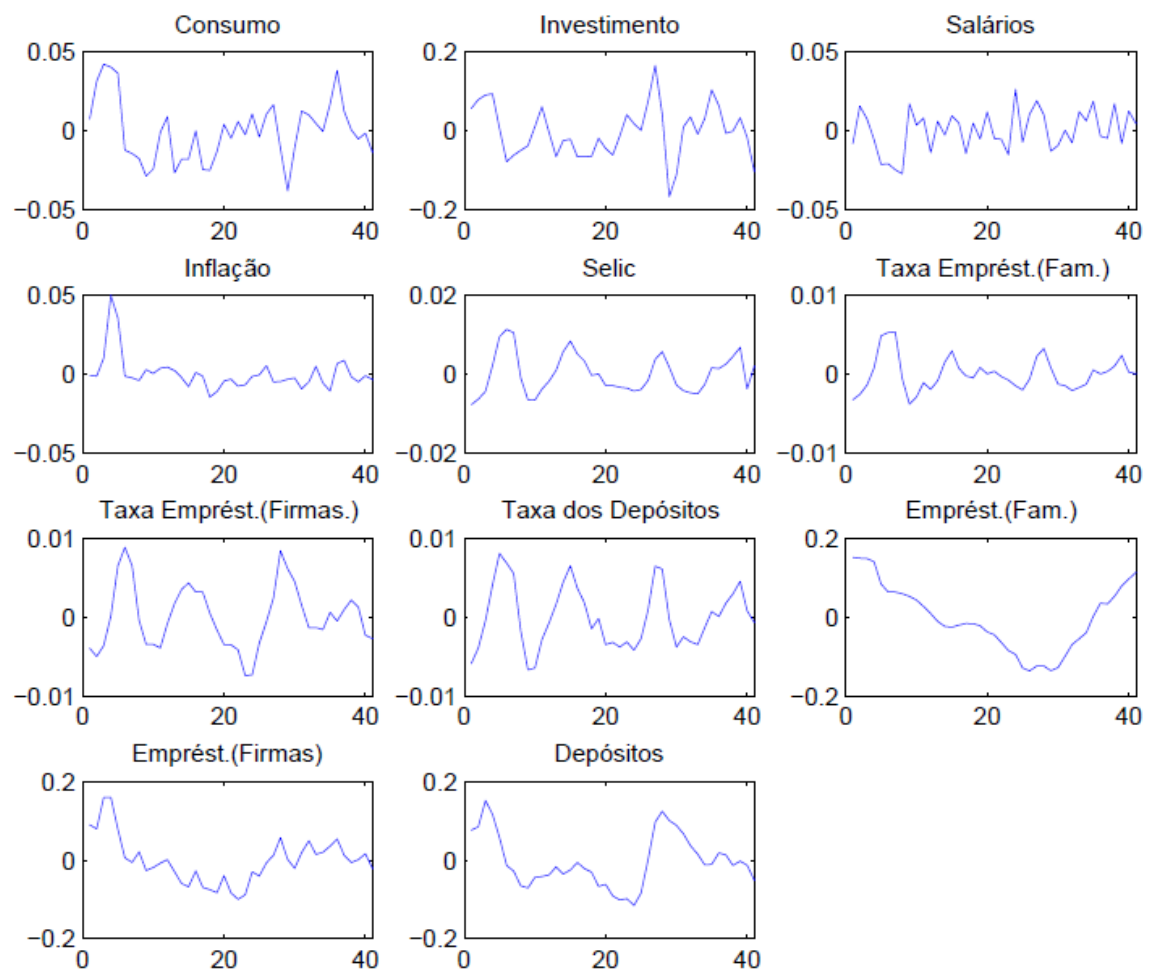

Fonte: Elaboração própria a partir de dados do BCB, BNDES e IBGE.

Nota: As séries de inflação e de inflação de salários são expressas em base trimestral e em pontos percentuais, com base na diferença em relação à média. As demais séries, que apresentaram tendência, são expressas como log-desvios em torno da tendência calculada com o filtro HP $(\lambda=1600)$. As séries de volume são expressas em termos reais e as taxas de juros em termos nominais. 


\subsection{Calibração}

A Tabela 1 apresenta os valores dos parâmetros calibrados, os quais são responsáveis pela definição dos valores das variáveis no estado estacionário. Da literatura, foram obtidos os valores do fator de desconto das famílias pacientes $\beta_{P}$, do inverso da elasticidade de Frisch $\varphi$, das elasticidades de substituição no mercado de bens $\varepsilon^{y}$ e de trabalho $\varepsilon^{l}$ (CASTRO; GOUVEA; MINELLA; SANTOS; SOBRINHO, 2011); da parcela do capital na função de produção $\alpha$ (GOMES; PESSOA; VELOSO, 2003); da parcela de renda do trabalho das famílias pacientes $\mu$ e do peso do bem imobiliário na função utilidade $\varepsilon^{h}$ (GERALI; NERI; SESSA; SIGNORETTI, 2010). A função $\psi\left(u_{t}\right)$ também é especificada como no estudo de Gerali, Neri, Sessa e Signoretti (2010), de maneira que $\xi_{1}$ é determinado pela taxa de retorno sobre o capital no estado estacionário, obtida a partir dos demais parâmetros calibrados, e $\xi_{2}=0,1 * \xi_{1}$.

Tabela 1 - Parâmetros calibrados

\begin{tabular}{|c|c|c|}
\hline Parâmetros & Descrição & Valor \\
\hline$\beta_{P}$ & Fator de desconto das famílias pacientes & 0,989 \\
\hline$\beta_{I}$ & Fator de desconto das famílias impacientes & 0,96 \\
\hline$\beta_{E}$ & Fator de desconto dos empreendedores & 0,96 \\
\hline$\pi$ & Inflação no estado estacionário & 0,045 \\
\hline$\varphi$ & Inverso da elasticidade de Frisch & 1,0 \\
\hline$\mu$ & Parcela de renda das famílias impacientes & 0,8 \\
\hline$\varepsilon^{h}$ & Peso do bem imobiliário na função utilidade & 0,2 \\
\hline$\alpha$ & Parcela do capital na função de produção & 0,40 \\
\hline$\delta$ & Taxa de depreciação do capital & 0,035 \\
\hline$\varepsilon^{y}$ & Markup no mercado de bens finais & 11 \\
\hline$\varepsilon^{l}$ & Markup no mercado de trabalho & 3 \\
\hline$m^{I}$ & Loan-to-value das famílias impacientes & 0,15 \\
\hline$m^{E}$ & Loan-to-value dos empreendedores & 0,085 \\
\hline$v^{b}$ & Relação ótimo do capital bancário & 0,17 \\
\hline$\varepsilon^{d}$ & Markdown nas taxas de depósito & $-12,62$ \\
\hline$\varepsilon^{b H}$ & Markup nas taxas de emprétimos às famílias impacientes & 5,36 \\
\hline$\varepsilon^{b E}$ & Markup nas taxas de empréstimos aos empreendedores & 2,73 \\
\hline$\delta^{b}$ & Taxa de depreciação do capital bancário & 0,0944 \\
\hline$\xi_{1}$ & Parâmetro relativo ao custo de ajustamento da utilização do & 0,0755 \\
\hline$\xi_{2}$ & Parâmetro relativo ao custo de ajustamento da utilização do & 0,00755 \\
\hline
\end{tabular}

Fonte: Elaboração própria. 
A inflação de estado estacionário $\pi$ foi definida em função da meta estabelecida pelo Conselho Monetário Nacional, atualmente fixada em 4,5\% a.a. A taxa de depreciação do capital foi fixada em 3,5\% ao trimestre, de forma a garantir uma relação entre investimento e produto de aproximadamente $17 \%$ no estado estacionário, compatível com o calibrado por Sachsida, Junior e Gomes (2002).

Os parâmetros referentes às taxas de intermediação financeira foram estabelecidos com o objetivo de gerar markups e markdown compatíveis com as médias históricas obtidas em comparação com a taxa básica de juros, aqui definida pela Taxa Selic. Dessa maneira, assumindo uma elasticidade de substituição nas taxas dos empréstimos às famílias $\varepsilon^{b H}$ de 5,36, obtém-se um markup $\left(\frac{\varepsilon^{b H}}{\varepsilon^{b H}-1}\right)$ de aproximadamente $23 \%$ (ou 222 pontos base) sobre a taxa instrumento da política monetária. A relação ótima de capital bancário $v^{b}$ é fixada em $17 \%$, compatível com o nível de capital corrente do sistema financeiro. A taxa de depreciação do capital bancário $\delta^{b}$ é definida em 0,0944 , garantindo que essa relação de capital ótima seja alcançada no estado estacionário.

Finalmente, os fatores de desconto das famílias impacientes $\beta_{I}$ e dos empreendedores $\beta_{E}$, bem como os valores da relação loan-to-value dos empréstimos às famílias impacientes $m^{I}$ e empreendedores $m^{E}$ foram determinados de modo a se obterem valores de estado estacionário dos depósitos e empréstimos, como proporção do produto, compatíveis com os dados da economia brasileira. A Tabela 2 apresenta a relação entre determinadas variáveis endógenas no estado estacionário com base nos parâmetros aqui calibrados. Os demais parâmetros, responsáveis por determinar a dinâmica do modelo, foram estimados com base no método de estimação bayesiano.

Tabela 2 - Relações no estado estacionário

\begin{tabular}{ll}
\hline \multicolumn{1}{c}{ Variável } & Valor \\
\hline Consumo (\% Produto) & $83,01 \%$ \\
Investimento (\% Produto) & $16,99 \%$ \\
Taxa dos depósitos (a.a.) & $8,92 \%$ \\
Taxa básica (a.a.) & $9,63 \%$ \\
Taxa dos empréstimos às famílias (a.a.) & $11,84 \%$ \\
Taxa dos empréstimos às empresas (a.a.) & $15,19 \%$ \\
Empréstimo às familias (\% Total) & $18,31 \%$ \\
Empréstimo às empresas (\% Total) & $81,69 \%$ \\
\hline
\end{tabular}

Continua... 


\begin{tabular}{lc}
\hline \multicolumn{1}{c}{ Variável } & Valor \\
\hline Crédito (\% Produto) & $47,13 \%$ \\
Depósitos (\% Produto) & $39,12 \%$ \\
Capital Bancário (\% Produto) & $8,01 \%$ \\
\hline
\end{tabular}

Fonte: Elaboração própria.

\subsection{Resultados da Estimação}

Foram estimados 38 parâmetros por meio do método bayesiano (CANOVA, 2007). Para os parâmetros relativos à regra de política monetária, os parâmetros de indexação de preços e salários e os parâmetros referentes aos coeficientes autorregressivos e desvios padrões dos choques presentes nos processos exógenos, optou-se por utilizar as distribuições a priori definidas por Castro, Gouvea, Minella, Santos e Sobrinho (2011), que se basearam em informações mais precisas sobre os parâmetros relativos à conjuntura brasileira. Para os demais parâmetros, seguiu-se a definição de Gerali, Neri, Sessa e Signoretti (2010). A Tabela 3 apresenta a forma funcional, a média e o desvio padrão das distribuições a priori dos parâmetros estruturais estimados, excetuando-se os parâmetros referentes aos processos exógenos. Para estes, a distribuição a priori foi definida como uma distribuição beta, com média igual a 0,80 e desvio padrão de 0,10, no caso dos coeficientes autorregressivos, e uma distribuição gama inversa, com média igual a 1,00 e desvio padrão de 50,00 , para os desvios padrões dos seus respectivos choques.

Tabela 3 - Parâmetros estimados: estruturais

\begin{tabular}{lllllllll}
\hline & \multirow{2}{*}{ Parâmetros } & \multicolumn{3}{c}{ Prior } & \multicolumn{5}{c}{ Posterior } \\
\cline { 3 - 9 } & & Distrib. & Média & D.P. & Média & Mediana & $\mathbf{2 , 5 \%}$ & $\mathbf{9 7 , 5 \%}$ \\
\hline$a^{h}$ & Coeficiente de hábito & Beta & 0,85 & 0,05 & 0,915 & 0,916 & 0,883 & 0,947 \\
$\kappa_{p}$ & Rigidez de preços & Gama & 50,00 & 20,00 & 129,289 & 127,705 & 92,436 & 165,128 \\
$\kappa_{w}$ & Rigidez de salários & Gama & 50,00 & 20,00 & 64,488 & 62,221 & 34,740 & 92,971 \\
$\mathrm{i}_{\mathrm{p}}$ & Indexação de preços & Beta & 0,65 & 0,20 & 0,692 & 0,711 & 0,431 & 0,979 \\
$\mathrm{i}_{\mathrm{w}}$ & Indexação de salários & Beta & 0,65 & 0,20 & 0,347 & 0,323 & 0,071 & 0,612 \\
$\varphi_{\pi}$ & Coef. inf. regra de Taylor & Normal & 2,00 & 0,35 & 1,817 & 1,811 & 1,225 & 2,372 \\
$\varphi_{R}$ & Coef. autorreg. regra de & Beta & 0,60 & 0,15 & 0,877 & 0,887 & 0,792 & 0,964 \\
& Taylor & & & & & & & \\
$\varphi_{y}$ & Coef. produto regra de & Gama & 0,25 & 0,10 & 0,296 & 0,281 & 0,110 & 0,477 \\
& Taylor & & & & & & & \\
$\kappa_{i}$ & Custo ajust. investimento & Gama & 2,50 & 1,00 & 2,566 & 2,472 & 1,408 & 3,673 \\
$\kappa_{d}$ & Custo ajus. taxa de dep. & Gama & 10,00 & 2,50 & 13,754 & 13,593 & 9,523 & 17,892 \\
\hline & & & & & & & \multicolumn{3}{c}{ Continua... }
\end{tabular}


Conclusão.

\begin{tabular}{llllllllc}
\hline \multirow{2}{*}{ Parâmetros } & \multicolumn{3}{c}{ Prior } & \multicolumn{4}{c}{ Posterior } \\
\cline { 2 - 8 } & Distrib. & Média & D.P. & Média & Mediana & $\mathbf{2 , 5 \%}$ & $\mathbf{9 7 , 5 \%}$ \\
\hline$\kappa_{b E}$ & $\begin{array}{l}\text { Custo ajus. taxa } \\
\text { empreend. }\end{array}$ & Gama & 3,00 & 2,50 & 7,938 & 7,729 & 4,886 & 10,919 \\
$\kappa_{b H}$ & $\begin{array}{l}\text { Custo ajust. taxa fam. } \\
\text { impac. }\end{array}$ & Gama & 6,00 & 2,50 & 16,780 & 16,600 & 11,799 & 21,821 \\
$\kappa_{K b}$ & $\begin{array}{l}\text { Custo ajust. cap. } \\
\text { bancário }\end{array}$ & Gama & 10,00 & 5,00 & 3,327 & 3,095 & 0,823 & 5,724 \\
\hline
\end{tabular}

Fonte: Elaboração própria.

Inicialmente, realizou-se a estimação dos parâmetros estruturais sem a incorporação dos instrumentos de regulação macroprudencial, ou seja, assumindo a ausência de necessidade de manutenção de ativos de alta liquidez $\left(\tau_{t}^{L C R}=0\right)$, a falta de sensibilidade ao ciclo econômico dos fatores de ponderação de risco dos empréstimos $\left(w_{t}=1\right)$ e uma relação ótima de capital constante $\left(v^{b}=0,17\right)$. A distribuição a posteriori foi obtida a partir do algoritmo de Metropolis-Hastings, que consiste em um método de Monte Carlo via Cadeias de Markov (MCMC), com três cadeias separadas contendo 1.000.000 de iterações cada. ${ }^{3}$ A avaliação de convergência das cadeias foi realizada com base nas estatísticas propostas por Brooks e Gelman (1998). A Figura 2 apresenta as densidades marginais das distribuições a priori e a posteriori para determinados parâmetros.

3 Utilizou-se um fator de escala compatível com taxas de aceitação de aproximadamente $25 \%$. 
Figura 2 - Distribuições a priori (anterior) e a posteriori (posterior)
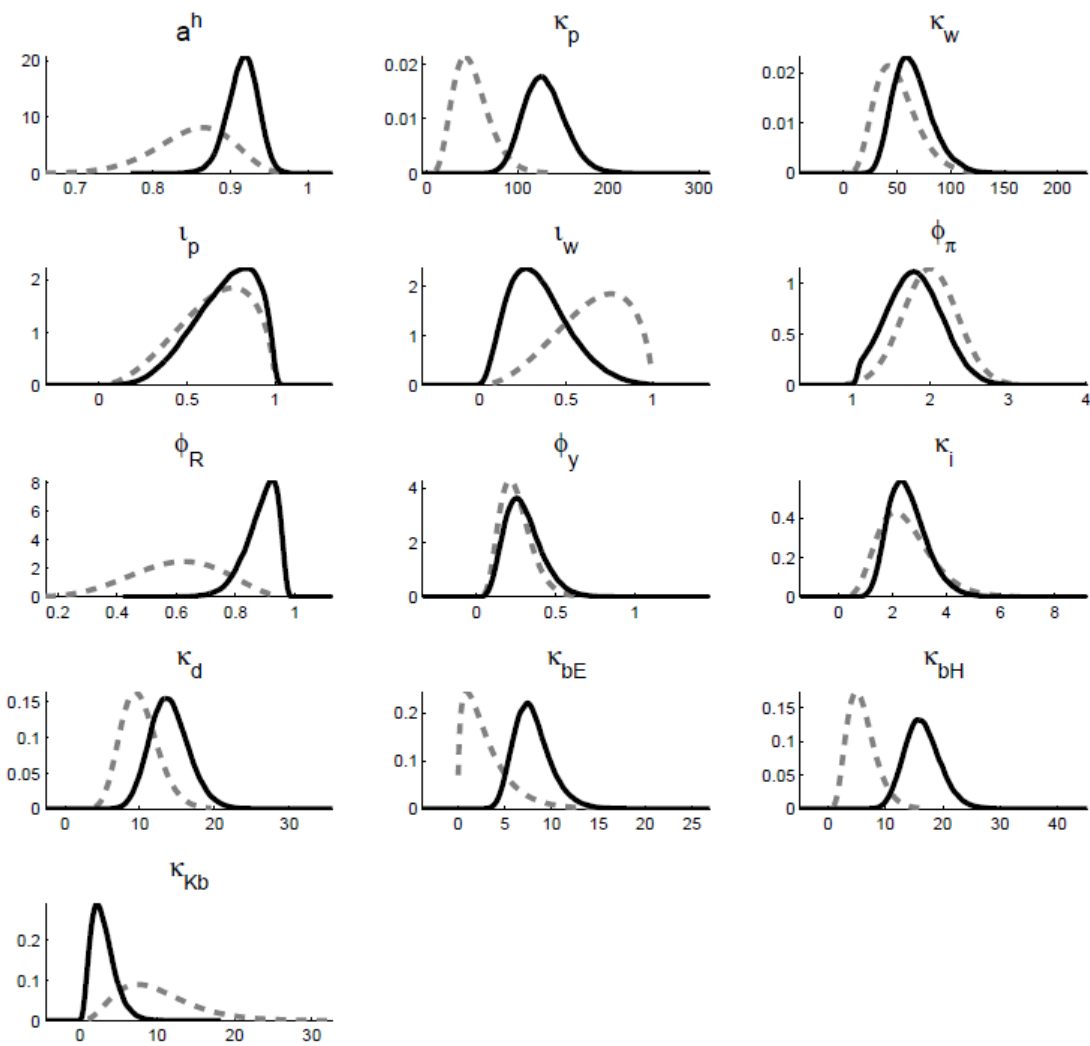

$$
\text { - = - Prior — Posterior }
$$

Fonte: Elaboração própria.

Nota: As densidades marginais das distribuições a priori são obtidas a partir das formas funcionais especificadas, e as das distribuições a posteriori são obtidas por meio do algoritmo de Metropolis-Hastings com três cadeias separadas de 1.000 .000 de iterações cada.

Os valores das médias e medianas de cada parâmetro estimado, bem como dos seus quantis, 2,5\% e 97,5\%, encontram-se expostos nas Tabelas 3 e 4 . Comparativamente às estimativas de Gerali, Neri, Sessa e Signoretti (2010), os choques mostram-se menos persistentes com base nos dados da economia brasileira, o que poderia ser justificado por sua maior volatilidade e exposição a choques externos, não contemplados nessa modelagem. Os parâmetros referentes ao sistema financeiro também apresentam diferenças significativas. Os custos de ajustamento das taxas de depósito se mostraram maiores no Brasil, enquanto a estimativa para o custo de ajustamento do capital bancário foi substancialmente inferior. Vale observar, no entanto, que esse último parâmetro se mostrou fracamente identificado no 
estudo da União Europeia, revelando uma maior relevância dos dados brasileiros em sua estimação. Ainda, ao contrário dos valores estimados para a União Europeia, em que os custos de ajustamento das taxas de empréstimos às famílias impacientes e às firmas se apresentaram muito próximos, para os dados brasileiros o custo referente aos empréstimos às famílias se revelou significativamente superior.

Tabela 4 - Parâmetros estimados: choques exógenos

\begin{tabular}{|c|c|c|c|c|c|}
\hline \multirow{2}{*}{\multicolumn{2}{|c|}{ Parâmentros }} & \multicolumn{4}{|c|}{ Posterior } \\
\hline & & \multirow[t]{2}{*}{ Média } & \multirow[t]{2}{*}{ Mediana } & \multirow[t]{2}{*}{$2,5 \%$} & \multirow[t]{2}{*}{$\mathbf{9 7 , 5 \%}$} \\
\hline Coefic & tes AR & & & & \\
\hline$\rho_{z}$ & Preferência do consumidor & 0,162 & 0,144 & 0,004 & 0,307 \\
\hline$\rho_{a}$ & Choque tecnológico & 0,066 & 0,054 & 0,000 & 0,135 \\
\hline$\rho_{h}$ & Preferência do bem imobiliário & 0,484 & 0,486 & 0,104 & 0,871 \\
\hline$\rho m E$ & Loan-to-value das firmas & 0,052 & 0,042 & 0,000 & 0,107 \\
\hline$\rho m I$ & Loan-to-value das famílias impacientes & 0,528 & 0,537 & 0,142 & 0,919 \\
\hline$\rho_{d}$ & Markdown dos depósitos & 0,280 & 0,272 & 0,051 & 0,490 \\
\hline$\rho b H$ & Markup dos empréstimos às familias impacientes & 0,355 & 0,356 & 0,120 & 0,583 \\
\hline$\rho b E$ & Markup dos empréstimos às firmas & 0,338 & 0,335 & 0,094 & 0,573 \\
\hline$\rho q k$ & Eficiência no investimento & 0,719 & 0,733 & 0,557 & 0,889 \\
\hline$\rho_{y}$ & Markup do bem final & 0,769 & 0,928 & 0,218 & 1,000 \\
\hline$\rho_{l}$ & Markup dos salários & 0,437 & 0,444 & 0,219 & 0,653 \\
\hline$\rho K b$ & Capital bancário & 0,582 & 0,600 & 0,231 & 0,975 \\
\hline \multicolumn{6}{|c|}{$\begin{array}{l}\text { Desvios } \\
\text { Padrão }\end{array}$} \\
\hline$\sigma_{z}$ & Preferência do consumidor & 0,290 & 0,277 & 0,185 & 0,395 \\
\hline$\sigma_{a}$ & Choque tecnológico & 0,185 & 0,183 & 0,142 & 0,227 \\
\hline$\sigma_{h}$ & Preferência do bem imobiliário & 1,018 & 0,684 & 0,221 & 2,037 \\
\hline$\sigma m E$ & Loan-to-value das firmas & 0,127 & 0,126 & 0,104 & 0,148 \\
\hline$\sigma m I$ & Loan-to-value das famílias impacientes & 0,127 & 0,126 & 0,104 & 0,148 \\
\hline$\sigma_{d}$ & Markdown dos depósitos & 0,190 & 0,188 & 0,149 & 0,231 \\
\hline$\sigma b H$ & Markup dos empréstimos às familias impacientes & 0,266 & 0,261 & 0,190 & 0,340 \\
\hline$\sigma b E$ & Markup dos empréstimos às firmas & 0,399 & 0,385 & 0,260 & 0,533 \\
\hline$\sigma_{q k}$ & Eficiência no investimento & 0,277 & 0,261 & 0,165 & 0,384 \\
\hline$\sigma_{R}$ & Política Monetária & 0,126 & 0,124 & 0,103 & 0,147 \\
\hline$\sigma_{y}$ & Markup do bem final & 1,330 & 1,267 & 0,289 & 2,205 \\
\hline$\sigma_{1}$ & Markup dos salários & 3,036 & 2,892 & 1,580 & 4,470 \\
\hline$\sigma K b$ & Capital bancário & 0,129 & 0,127 & 0,106 & 0,151 \\
\hline
\end{tabular}

Fonte: Elaboração própria. 
O parâmetro de rigidez de salários mostrou-se fracamente identificado nos dados, sendo bastante sensível a variações na média de sua distribuição a priori. Isso se deve, em parte, à dificuldade de obtenção de uma série de salários consistente para a economia brasileira, revelando uma possível inadequação da série aqui utilizada. Com relação à rigidez nominal de preços, as estimativas mostraram uma elevada rigidez e indexação em nossa economia. No tocante aos parâmetros associados à política monetária, as estimativas estão bastante em linha com a literatura, mostrando uma fraca identificação do coeficiente de resposta ao produto e uma elevada persistência.

Ainda, os parâmetros relacionados às rigidezes no ajustamento das taxas de juros praticadas no mercado financeiro revelam também uma maior flexibilidade na variação das taxas dos empréstimos às firmas, comparativamente às taxas dos depósitos e empréstimos às famílias impacientes. Esse resultado parece bastante natural, decorrente de uma maior influência regulatória sobre os financiamentos imobiliários e depósitos de poupança. O custo de ajustamento do capital bancário, por sua vez, apresenta valor inferior ao estimado para o sistema europeu, cuja mediana equivale a $11,07 .{ }^{4}$ Esse parâmetro determina o custo incorrido pela instituição ao se distanciar, para cima ou para baixo, do nível de capital $v^{b}$ definido de forma exógena. No modelo aqui estimado, em que as instituições financeiras acumulam capital por meio de lucros acumulados, um baixo valor para esse parâmetro sinaliza que as instituições são menos pressionadas a alterar suas taxas de juros correntes em função de resultado anteriores que, eventualmente, desviaram-na de sua relação ótima de capital. ${ }^{5}$

Finalmente, com o objetivo de avaliar o efeito da incorporação de determinados instrumentos de regulamentação prudencial sobre as estimativas dos parâmetros, foram realizadas novas estimações incorporando inicialmente apenas o instrumento de liquidez de curto prazo $\left(\tau_{t}^{L C R}=35 \%\right.$ e $\left.R_{t}^{L C R}=r_{t}\right)$ e, posteriormente, o fator de ponderação de risco pró-cíclico $\left(\tau_{t}^{L C R}=35 \%, R_{t}^{L C R}=r_{t}, \rho=0,94\right.$ e $\left.\chi=-10\right)$. Observa-se que, em geral, as estimativas sofrem pequenas alterações após as modificações no modelo, permanecendo dentro do intervalo de confiança da estimativa original. O valor de 35\% foi definido considerando-se o saldo médio de depósitos compulsórios acrescido do montante de títulos e valores mobiliários de propriedade das instituições financeiras. ${ }^{6}$ Ainda, como o modelo interno de risco de crédito proposto por Basileia II ainda não foi implementado de forma abrangente em várias

$4 \quad$ Ver Gerali, Neri, Sessa e Signoretti (2010).

5 Como o modelo se utiliza de custos de ajustamento definidos de modo ad hoc para descrever as rigidezes presentes na economia, optou-se pela inclusão de modalidades de crédito direcionado nos segmentos de pessoa jurídica e natural nas séries de empréstimos, de maneira a capturar os efeitos das fricções geradas por essas modalidades nos efeitos estimados sobre as variáveis macroeconômicas de interesse.

6 Ver Brandi (2013) e Brandi e De Andrade (2018) para maior detalhamento. 
jurisdições, o que a investigação empírica bastante limitada, utiliza-se os parâmetros de prociclicidade propostos por Angelini, Neri e Panetta (2011).

\subsection{Propriedades do Modelo}

Os parâmetros anteriormente estimados são agora calibrados com base no valor da mediana de sua distribuição a posteriori, ${ }^{7}$ com a finalidade de avaliar o efeito dos choques exógenos sobre a dinâmica do modelo. A incorporação dos ativos ponderados por risco apurados de forma procíclica produz um efeito generalizado de amplificação desses efeitos.

Na prática, o sistema financeiro se torna pró-cíclico quando o comportamento das instituições financeiras tende a reforçar as oscilações dos ciclos econômicos. Em períodos de crescimento econômico, os bancos tendem a se comportar de maneira excessivamente otimista, o que provoca um certo viés nos processos de avaliação dos ativos e do risco de suas operações (BORIO; FURFINE; LOWE, 2001). Na prática, esse sentimento pode conduzir à sobreavaliação de colaterais, provisões insuficientes e redução indevida nos spreads de determinadas operações que, reforçadas pelo crescimento da economia, geram um ciclo de elevada lucratividade no setor bancário e na expansão do crédito.

Lowe (2002) observa que períodos de crescimento econômico associados a um elevado nível de risco de crédito surgem concomitantemente a períodos de rápida expansão no crédito, aumentos substanciais nos preços dos ativos e alto nível de investimento frequentemente sintomáticos do surgimento de desequilíbrios financeiros. Em períodos de contração econômica, ao contrário, um sentimento pessimista, de elevada aversão ao risco, pode conduzir a um corte exagerado na concessão do crédito, o que reforçaria a queda nas variáveis da economia real.

O choque de política monetária corresponde a um aumento não esperado na taxa anual de juros correspondente a 50 pontos base. Define-se igualmente de forma arbitrária o choque tecnológico, de modo que a produtividade total dos fatores aumente $2,5 \%$, com um coeficiente de correlação serial igual a 0,9 . O choque no capital bancário, por sua vez, é ajustado de maneira a destruir inesperadamente $5 \%$ do capital bancário.

Os resultados para o choque de política monetária são bastante convencionais e em linha com o modelo estimado para a zona do euro (GERALI; NERI; SESSA; SIGNORETTI, 2010). O aumento na taxa de juros instrumento de política monetária provoca um aumento no custo dos empréstimos e uma redução no preço

7 Em função da fraca identificação do parâmetro $\kappa_{\omega}$, atribui-se a ele o valor da mediana da distribuição a posteriori do parâmetro $\kappa$. Essa decisão se apoia em resultados empíricos anteriores para a economia brasileira em que os parâmetros de rigidez de salários e preços possuem estimativas bem próximas. 
dos ativos (colateral), com efeitos negativos sobre a demanda pelos empréstimos. Como consequência, investimento e consumo apresentam variações negativas, implicando em queda do produto e do nível de preços (inflação). A redução nos investimentos produz efeitos sobre a demanda por trabalho, reduzindo-se a renda do trabalho das famílias e o volume de depósitos das famílias pacientes. Com relação à atividade de intermediação financeira, inicialmente o aumento na margem de intermediação mais do que compensa a redução em seu volume, de modo que os lucros bancários tendem a crescer. Após certo período, os bancos começam a apresentar prejuízos à medida que o volume das operações tende a regredir de forma mais lenta ao estado estacionário.

O choque tecnológico, por sua vez, provoca um aumento na produtividade marginal do trabalho, aumentando o valor dos salários e reduzindo a demanda por mão de obra, dado que as firmas podem produzir a mesma quantidade de bem final com menos fatores de produção. Adicionalmente, as famílias tendem a reduzir sua carga de trabalho e a aumentar seu consumo decorrente de uma maior renda salarial. Consequentemente, observa-se uma redução na quantidade de trabalho na economia.

A resposta da inflação é imediata, atingindo uma queda máxima de três pontos percentuais logo no segundo semestre, com o movimento de regresso ao equilíbrio se iniciando logo no quarto semestre. A política monetária se ajusta à variação da inflação promovendo uma redução da taxa básica de juros, derrubando também as demais taxas praticadas no mercado financeiro. Como resultado, aumenta-se a demanda por empréstimos tanto pelas famílias impacientes quanto pelas firmas, no médio prazo. Consumo e investimento reagem positivamente ao choque, apresentando volatilidades semelhantes, com variação máxima de aproximadamente $1 \%$ em relação ao estado estacionário. Nota-se, no entanto, uma queda inicial no investimento que perdura pelos dois trimestres iniciais, que se deve majoritariamente pela queda abrupta no preço do capital no primeiro trimestre.

Com o objetivo de se avaliar como choques no capital bancário são transmitidos através da economia, simula-se um choque exógeno calibrado de maneira a destruir inesperadamente $5 \%$ do capital bancário. Após o choque, os bancos tornam-se excessivamente alavancados e com elevado custo associado ao requerimento de capital. Para reduzir a demanda por empréstimos, aumentam-se suas taxas de juros. As firmas, por sua vez, considerando que o custo de utilização do capital se reduz relativamente ao custo de capital, diminuem o investimento e aumentam a demanda por mão de obra, com efeitos positivos sobre os salários. Esse aumento na renda salarial das famílias sustenta o nível de consumo no curto prazo, entretanto, a persistência na deterioração das condições financeiras impede uma recuperação rápida, promovendo efeitos negativos na atividade econômica sobre 
prazos mais longos. A inflação oscila muito pouco e a política monetária promove leves alterações para se ajustar a essas variações.

A Tabela 5 apresenta as diferenças entre os modelos que serão analisados. O modelo base simula o ambiente sob o regime de Basileia I, em que os fatores de ponderação de risco são invariantes no tempo $\left(w_{t}=1\right)$. O modelo BII (Basileia II) incorpora sensibilidade ao risco na definição dos fatores de ponderação de risco. Como referência, utilizam-se os valores estimados por Angelini, Enria, Neri, Panetta e Quagliariello (2010), que definem a dinâmica procíclica dos fatores de ponderação de risco para os empréstimos às firmas. Em seguida, utiliza-se um modelo contendo uma maior sensibilidade ao risco na definição dos fatores de ponderação de risco (BII (x5)). Finalmente, define-se um modelo contendo menor grau de persistência (BII $(x 5$ e $\rho<)$ ).

Tabela 5 - Características dos modelos

\begin{tabular}{lll}
\hline Modelo & $\rho_{\omega}$ & $\chi_{\omega}$ \\
\hline Base (BI) & - & - \\
BII & 0,94 & -10 \\
BII $(x 5)$ & 0,94 & -50 \\
BII $(x 5$ e $\rho<)$ & 0,90 & -50 \\
\hline
\end{tabular}

Fonte: Elaboração própria.

As Figuras 3, 4 e 5 apresentam os resultados das funções impulso-resposta para choques de política monetária, tecnológico e no capital bancário. As variáveis de volume são expressas em termos de variação percentual em relação ao valor do estado estacionário. As taxas de juros, o spread e a inflação são expressos em termos da diferença em pontos percentuais em relação ao valor do estado estacionário. O índice de Basileia representa o valor efetivo. 
Figura 3 - Choque de política monetária: FPR pró-cíclico
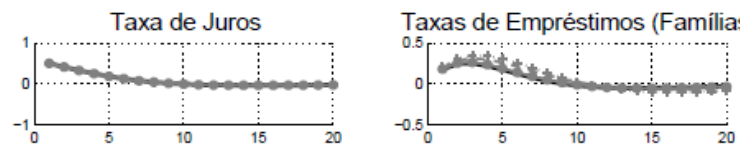

Inflação
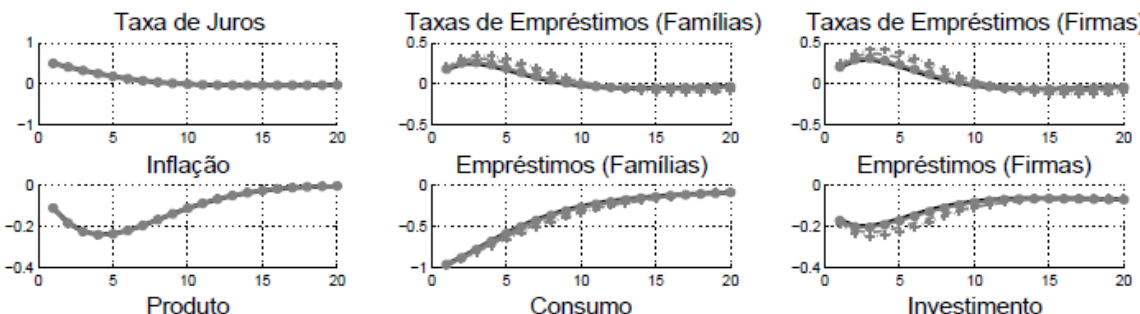

Produto

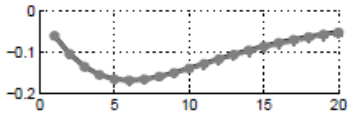

Taxas de Depósitos
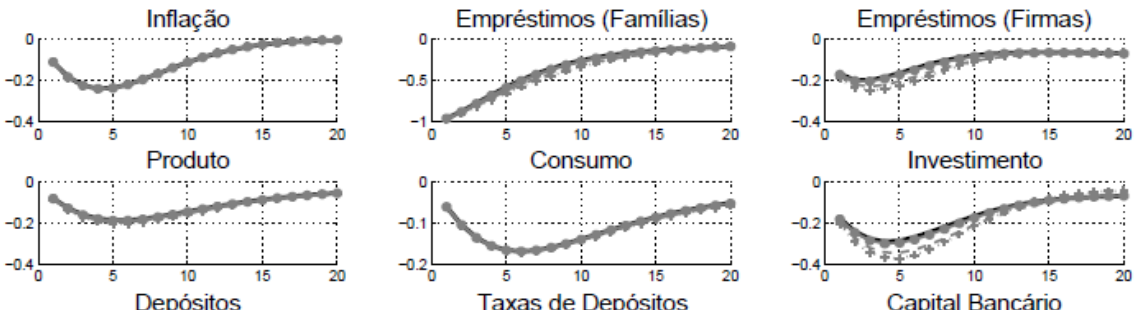

Depósitos

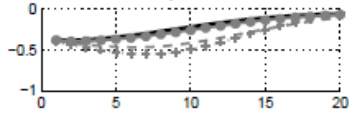

Spread

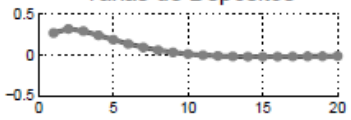

Lucro dos Bancos

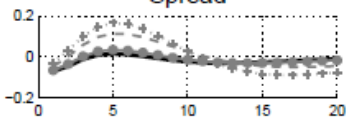

FPR BH

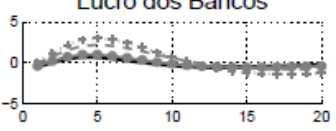

FPR BE

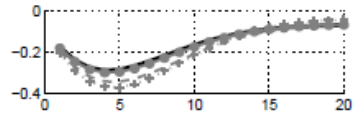

Capital Bancário

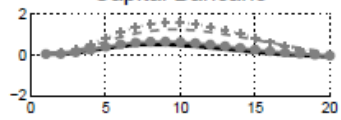

Índice de Basiléia (Cap/Ativos)
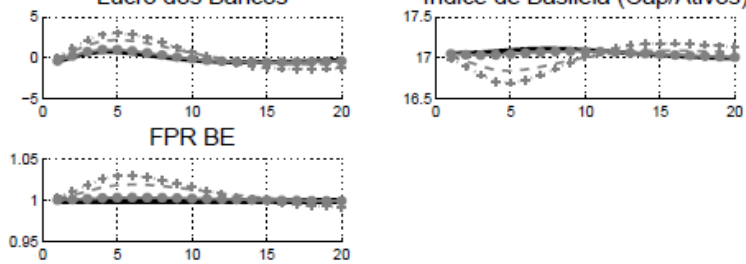

$\longrightarrow$ BI $\rightarrow$ BII --- BII $(x 5) \cdots+\cdots$ BII $(x 5$ e $\rho<)$

Fonte: Elaboração própria. 
Figura 4 - Choque tecnológico: FPR pró-cíclico
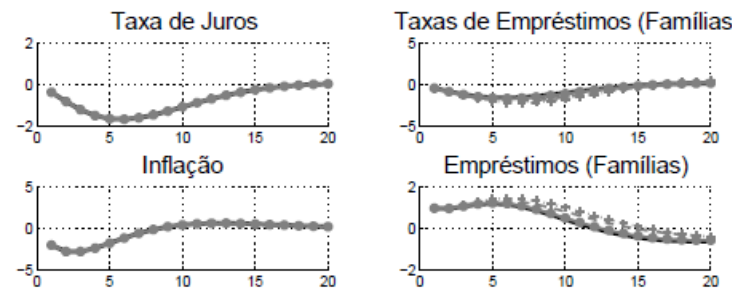

Produto

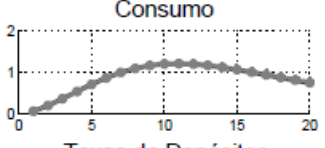

Taxas de Empréstimos (Firmas)

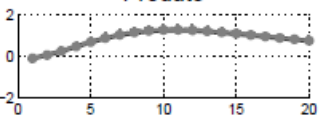

Depósitos

Taxas de Depósitos

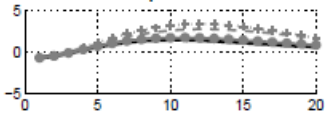

Spread

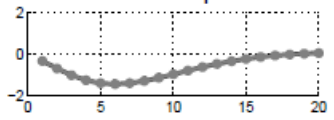

Lucro dos Bancos
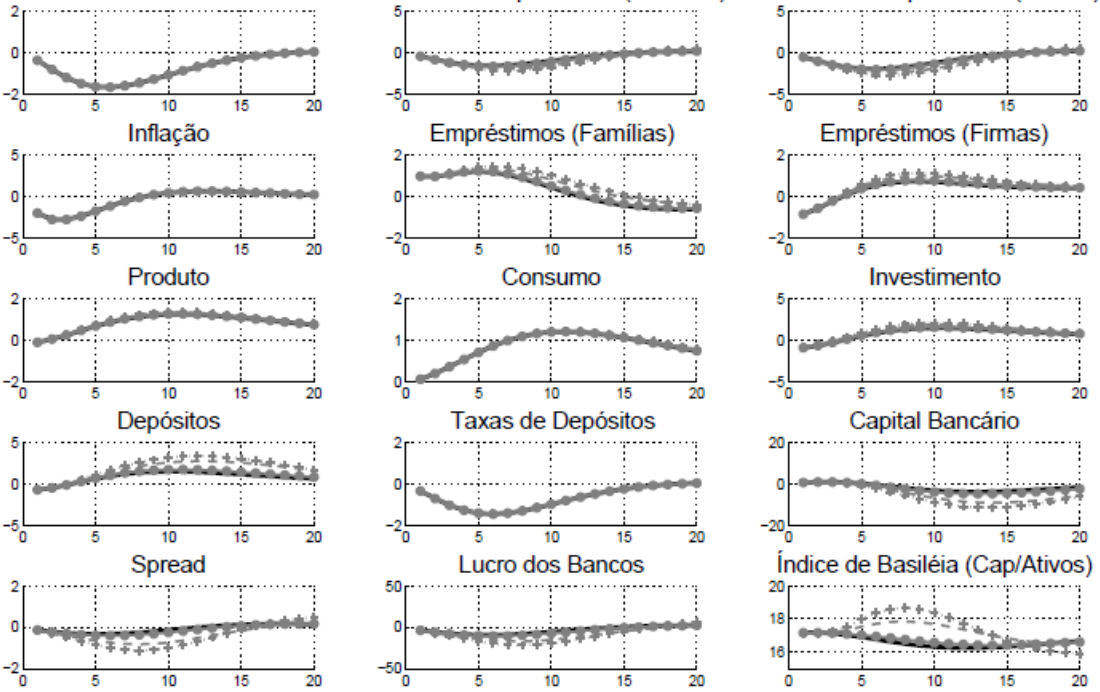

Empréstimos (Firmas)

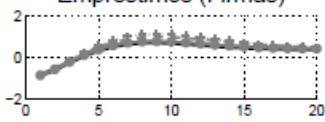

Investimento

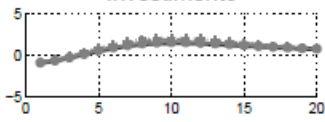

Capital Bancário

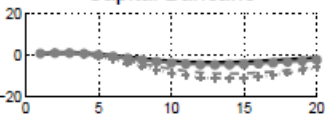

Índice de Basiléia (Cap/Ativos)

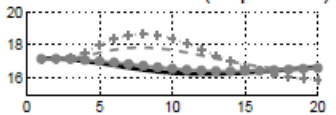

FPR BE
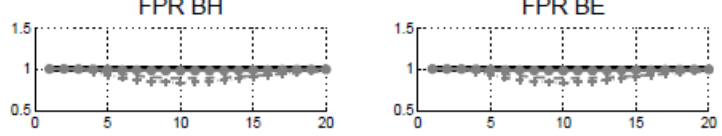

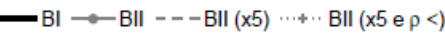

Fonte: Elaboração própria. 
Figura 5 - Choque de capital bancário: FPR pró-cíclico
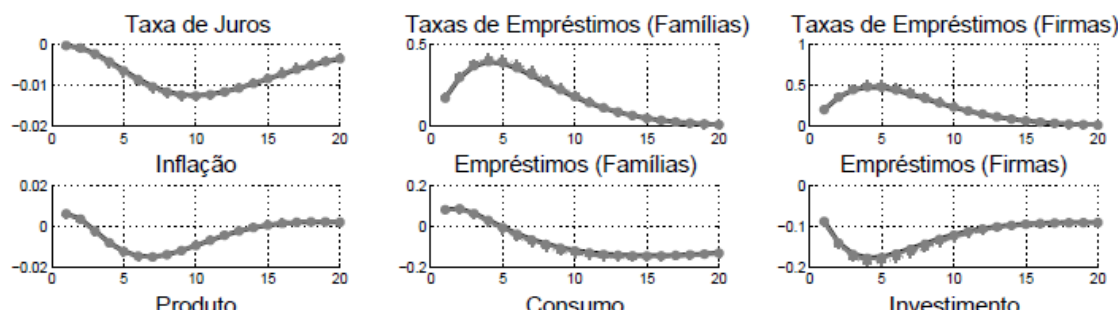

Empréstimos (Firmas)
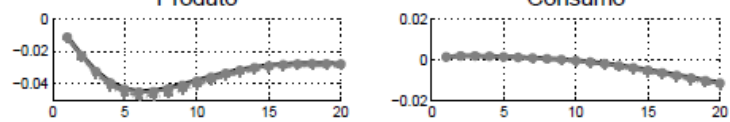

Taxas de Depósitos
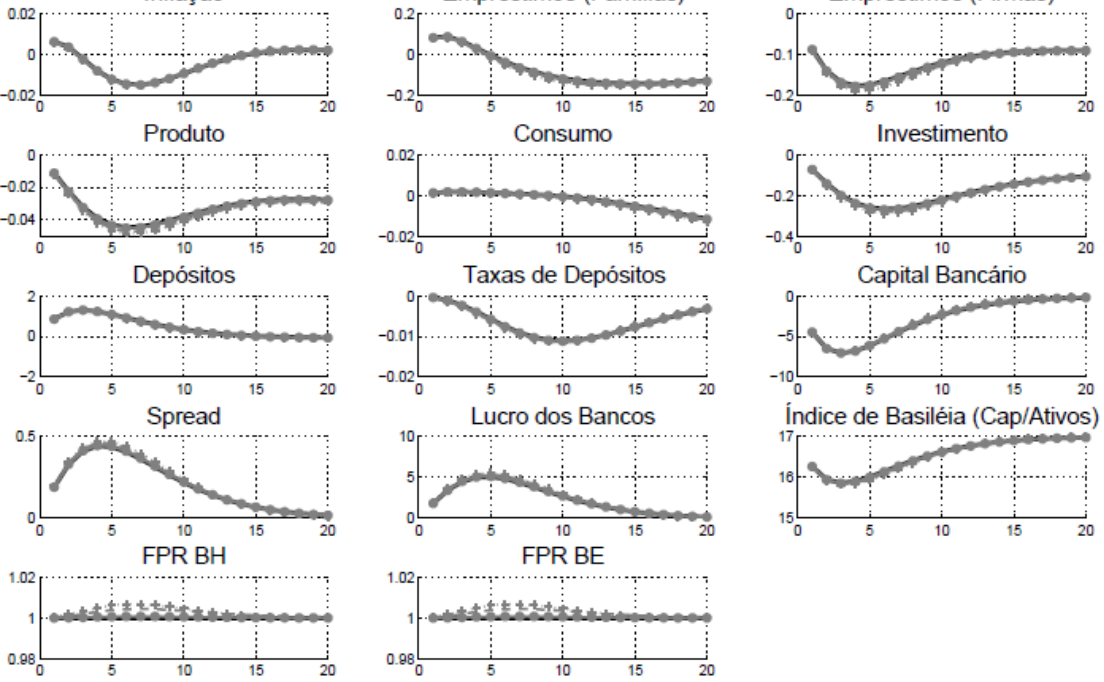

$\longrightarrow \mathrm{BI} \longrightarrow$ BII --- BII $(x 5) \cdots+\cdot \cdot$ BII $(x 5$ e $\rho<)$

Fonte: Elaboração própria.

\section{Efetividade da Política Macroprudencial}

O requerimento de capital contracíclico tem por objetivo proteger o sistema bancário de períodos de crescimento excessivo do crédito, os quais geralmente estão associados a períodos de elevado risco sistêmico, de forma a garantir condições necessárias para o bom funcionamento do sistema e manutenção de padrões de normalidade na oferta de crédito (BANK FOR INTERNATIONAL SETTLEMENTS, 2010). Com a implementação do arcabouço de Basileia III, as autoridades competentes de cada país ficam responsáveis por monitorar o crescimento do crédito doméstico e, baseadas em avaliações sobre seus potenciais efeitos sobre a estabilidade financeira de seu país, determinar o requerimento de capital adicional imposto às instituições, que deve oscilar entre $0 \%$ e 2,5\% dos ativos ponderados por risco. As regras determinam, ainda, que os aumentos no requerimento contracíclico devem ser anunciados com 12 meses de antecedência, proporcionando tempo suficiente para que as instituições sejam capazes de atender à exigência, 
e as reduções, ao contrário, devem produzir efeito imediatamente, favorecendo rapidamente as condições de oferta de crédito.

Uma referência de cálculo para a determinação do valor adequado para o requerimento de capital contracíclico baseia-se na relação crédito/PIB, que deve ser interpretada como ponto de partida para as análises promovidas pelas autoridades de supervisão domésticas. A partir de uma análise (DREHMANN; BORIO; GAMBACORTA; JIMENEZ; TRUCHARTE, 2010) contendo comparação entre diversos indicadores alternativos divididos em três grupos distintos, relativos a variáveis macroeconômicas, à performance do setor bancário e ao custo de financiamento, definiu-se o indicador crédito/PIB como principal referência para avaliação do risco sistêmico. Outras variáveis que podem ser utilizadas como indicadores sobre a evolução do risco sistêmico são os preços dos ativos, os spreads nas operações de financiamento, pesquisas sobre as condições de crédito, crescimento real do PIB, entre outras.

\subsection{Regra de Política Macroprudencial}

O instrumento por meio do qual se implementa a política macroprudencial neste trabalho é o requerimento de capital, assumindo que a autoridade de regulação tem a capacidade de influenciar o valor do nível ótimo de capital dos bancos, de acordo com a seguinte dinâmica:

$$
v_{t}^{b}=\left(1-\rho_{v}\right) v^{b}+\left(1-\rho_{v}\right) \chi_{v}\left(\log X_{t}-\log X_{t-4}\right)+\rho_{v} v_{t-1}^{b}
$$

na qual o parâmetro $v^{b}$ corresponde ao valor no estado estacionário de $v_{t}^{b}$, que corresponde ao nível ótimo de capital bancário na data $t, X_{t}$ denota alguma variável macroeconômica objeto da política macroprudencial, $\chi_{v}$ representa o parâmetro de sensibilidade dessa variável em relação ao nível de capital e $\rho_{v}$ consiste no parâmetro de persistência no ajuste da política.

Essa influência regulatória sobre a decisão de estrutura de capital das instituições financeiras pode ser justificada com base na Teoria do Buffer de Capital (VANHOOSE, 2007; PEURA; KEPPO, 2006; JOKIPII; MILNE, 2011), de acordo com a qual as instituições apresentam uma tendência a manter um excedente de capital (buffer) sobre o mínimo regulamentar, com o objetivo de mitigar eventuais custos decorrentes de uma maior intervenção da autoridade de supervisão. É importante observar que a atuação da autoridade de regulação não interfere no requerimento de capital do estado estacionário, apenas produz efeitos cíclicos conforme a evolução da variável macroeconômica de referência $X_{t}$, na proporção determinada pelo parâmetro de sensibilidade. Um valor positivo de $\chi_{v}$ indicaria uma política 
contracíclica, em que o requerimento de capital se torna maior em períodos de expansão econômica.

Ao contrário da política monetária, que influencia tanto as taxas de depósitos quanto as taxas dos empréstimos, o requerimento de capital promove impactos apenas nas taxas dos empréstimos, impondo custos de ajustamento quadráticos para variações na relação entre ativos e capital, o que permite que as autoridades possam promover efeitos independentes sobre as decisões de consumo dos agentes poupadores e tomadores de empréstimos (ANGELINI; NERI; PANETTA, 2011).

\subsection{Medida de Avaliação}

Desde Rotemberg e Woodford (1997) e Woodford (2002), tornou-se convencional a análise de bem-estar utilizando-se funções perdas quadráticas como aproximações da função de bem-estar dos agentes. Nos trabalhos de política monetária, geralmente essa função associa a perda de bem-estar a maiores volatilidades no produto e na inflação, em torno do estado estacionário. É comum, ainda, incorporar-se um peso para a volatilidade da taxa de juros objeto da política monetária, assumindo-se que tal variabilidade seria indesejada pela autoridade monetária.

Ao se avaliar o efeito de políticas macroprudenciais sobre o bem-estar dos agentes, seria necessária a implementação do método de perturbação contendo aproximações para a função utilidade e para as condições de equilíbrio de ordens superiores utilizadas neste trabalho. Com base nessa mesma restrição, por analogia ao usualmente utilizado na literatura de política monetária, alguns trabalhos incorporam funções perdas quadráticas associadas a variáveis relacionadas ao setor de crédito e financeiro. Dessa forma, busca-se caracterizar, mesmo que de forma simplificada e arbitrária, a função objetivo da autoridade macroprudencial na condução de suas políticas. Angelini, Neri e Panetta (2011), por exemplo, associam a volatilidade do volume de crédito como proporção do produto, bem como a própria volatilidade do instrumento de política macroprudencial à função perda da autoridade de regulação prudencial. Como proposto por Suh (2011), a avaliação será realizada com base numa medida representativa da dispersão da função impulso-resposta em torno do estado estacionário. Seja $Z_{t}$ uma variável endógena do modelo e $\varepsilon_{t}$, um choque exógeno ocorrido na data $t$, a medida de avaliação da política será dada por:

$$
\Omega_{t}=100 \times\left[\sum_{i=1}^{\infty} \beta^{i}\left(\frac{\partial \hat{z}_{t+i}}{\partial \varepsilon_{t}}\right)^{2}\right]^{-1 / 2}
$$




\subsection{Resultados}

Inicialmente, serão considerados cinco: o choque de política monetária $\varepsilon_{t}^{R}$, o choque tecnológico $\varepsilon^{a}$, o choque no capital bancário $\varepsilon^{K b}{ }_{t}$, o choque nas preferências dos consumidores $\varepsilon_{t}^{z}$ e o choque na demanda pelo bem imobiliário $\varepsilon_{t}^{h}{ }$. $O$ choque de política monetária corresponde a um aumento não esperado na taxa anual de juros correspondente a 50 pontos base, e o choque no capital bancário, por sua vez, é ajustado de maneira a destruir inesperadamente 5\% do capital bancário no primeiro trimestre. Os choques de demanda são representados por uma variação de um desvio padrão e o choque tecnológico é definido de modo que o produto apresente uma variação máxima equivalente a $0,5 \%$ antes de regressar a seu valor de estado estacionário.

Os parâmetros da política monetária, assim como os demais parâmetros estimados, são definidos com base na mediana de suas distribuições a posteriori ${ }^{8} \mathrm{e}$ os parâmetros responsáveis pela prociclicidade nos fatores de ponderação de risco são definidos conforme Angelini, Enria, Neri, Panetta e Quagliariello (2010). ${ }^{9}$ Por questões práticas, restringe-se o período de observação das respostas aos choques a 100 trimestres. O parâmetro $\beta$ é fixado em 0,9745 , representando a média entre os fatores de desconto intertemporal das famílias pacientes e impacientes.

A Tabela 6 apresenta as medidas de avaliação de política utilizadas nesse exercício. As medidas relacionadas a produto, inflação e variação da taxa de juros básica estão geralmente associadas aos objetivos da autoridade monetária, enquanto as demais se relacionam com os da autoridade prudencial. Distinguem-se, dessa maneira, diferentes objetivos a serem perseguidos pelas diferentes autoridades, o que permite avaliar de que modo a política contracíclica de requerimento de capital bancário atende a cada um desses objetivos, seja representado por um padrão de complementaridade e cooperação ou de conflito entre cada uma dessas políticas. Nesse exercício, vale lembrar, define-se um arranjo institucional bem específico, no qual o instrumento de política monetária é definido pela Regra de Taylor e considerado como dado para fins de avaliação da regra a ser definida para o instrumento de política prudencial.

\footnotetext{
8 Novamente, substitui-se o valor de $\kappa_{\omega}$ pelo de $\kappa_{\pi}$.

$9 \rho_{\omega}=0,94$ e $\chi_{\omega}=-10$.
} 
Tabela 6 - Medidas de avaliação de política

\begin{tabular}{c|c}
\hline Medidas de Avaliação & Variável de Referência \\
\hline$\Omega_{Y}$ & Produto \\
$\Omega_{\pi}$ & Inflação \\
$\Omega_{\Delta r}$ & Variação da taxa de juros básica \\
\hline$\Omega_{L / Y}$ & Credit gap \\
$\Omega_{L}$ & Crescimento do crédito \\
$\Omega_{K b}$ & Índice de capital bancário \\
$\Omega_{S p r}$ & Spread bancário \\
$\Omega_{\Delta} \mathbf{V}$ & Variação do nível ótimo de capital bancário \\
\hline
\end{tabular}

Fonte: Elaboração própria.

O Apêndice A apresenta as tabelas com as medidas de avaliação de política para diferentes variáveis endógenas do modelo variações relativas em comparação com o caso de ausência de política prudencial contracíclica $\left(\chi_{v}\right)$, para os diferentes choques mencionados. Os valores referentes ao parâmetro de persistência da política macroprudencial $\rho_{v}$ se mantêm fixos e iguais a 0,90, enquanto são alterados os valores referentes à sensibilidade da política em relação a variações no ciclo econômico, $\chi_{v}$. A magnitude desses valores foi definida de forma a permitir oscilações no nível ótimo de capital bancário consideradas aceitáveis de acordo com a referência internacional para a regulação prudencial do sistema financeiro.

Em geral, observa-se a capacidade da política macroprudencial na redução da volatilidade do ciclo econômico para os diferentes choques considerados. A inflação, ao contrário, apresenta uma variabilidade muito pequena para os diferentes perfis de política macroprudencial, revelando uma sensível elevação em sua volatilidade para os choques tecnológico e nas preferências do consumidor em uma política macroprudencial mais rígida.

Como resposta aos choques de política monetária, a contribuição da política macroprudencial para os objetivos da autoridade monetária não é tão conclusiva, com redução das volatilidades do produto, mas aumento no caso da inflação e taxa de juros. Com a intensificação da política, aumentando-se a sensibilidade em relação à variável de referência, as medidas referentes ao sistema financeiro apresentam comportamento diferenciado. Enquanto a medida relativa ao spread bancário apresenta uma tendência positiva com a intensificação da política, as demais medidas tendem a se reduzir inicialmente, até determinado ponto em que uma política macroprudencial mais ativa contribui para um aumento em suas volatilidades. 
Após um choque tecnológico, observa-se que a contribuição da política macroprudencial também não é conclusiva. Ao passo que se aumenta a volatilidade do produto com a intensificação da regra prudencial, as volatilidades da inflação e do instrumento de política monetária tendem a diminuir. Ainda, a medida de avaliação de política relativa à relação entre crédito e produto, um indicador bastante relevante para a avaliação da rigidez do sistema financeiro, tende a aumentar. As demais medidas referentes ao sistema financeiro apresentam aumento da volatilidade em casos de maior sensibilidade da regra prudencial a variações no ciclo econômico.

O choque no capital bancário, diferentemente dos demais tipos de choques aqui analisados, corresponde a um evento que se origina no próprio sistema financeiro. No que se refere ao objetivo da autoridade monetária, verifica-se a contribuição da política macroprudencial com redução da volatilidade do produto, inflação e taxa de juros básica. No tocante às medidas de avaliação de política relativas às variáveis do sistema financeiro, no entanto, observa-se uma tendência de redução de suas volatilidades, excetuando-se a medida referente ao índice de capital bancário. No entanto, apesar dessa última medida apresentar variações positivas em função da intensificação da política macroprudencial, ressalta-se que as variações são relativamente pequenas quando comparadas às variações nessa mesma medida de avaliação decorrentes dos demais choques aqui analisados. Adicionalmente, destaca-se o fato de que apenas para esse tipo de choque se observa uma redução na medida de avaliação referente ao spread bancário, para reduções relevantes na medida relativa ao produto.

Os choques nas preferências do consumidor e na demanda pelo bem imobiliário buscam representar os choques que têm origem no lado da demanda da economia. Em geral, verifica-se que a resposta do instrumento prudencial tende a deteriorar aquelas medidas associadas à estabilidade do sistema financeiro.

Com relação ao índice de capital bancário, apenas no caso do choque de política monetária observam-se algumas reduções em sua medida de avaliação de política após a intensificação da regra contracíclica. Ainda, no que diz respeito ao spread bancário, nota-se a redução da medida de avaliação correspondente apenas no caso de choque no capital bancário. Esses são mais uns indicadores sobre a adequação do uso do instrumento prudencial aqui analisado no caso de ocorrência de choques no capital bancário.

As Tabelas 7 e 8 permitem realizar essa mesma comparação entre os efeitos de diferentes choques sobre determinadas medidas de avaliação de políticas, considerando-se reduções na medida de avaliação associada à relação crédito/ produto equivalentes a $5 \%, 10 \%, 20 \%$ e $50 \%$. 
Tabela 7 - Efeito sobre $\Omega_{\pi}$

\begin{tabular}{c|ccccc}
\hline $\mathbf{V}$ ar. $\boldsymbol{\Omega}_{\mathbf{L} \mathbf{Y}}$ & $\boldsymbol{\varepsilon}^{\mathbf{R}}$ & $\boldsymbol{\varepsilon}^{\mathbf{a}}$ & $\boldsymbol{\varepsilon}^{\mathbf{K b}}$ & $\boldsymbol{\varepsilon}^{\mathbf{Z}}$ & $\boldsymbol{\varepsilon}^{\mathbf{h}}$ \\
\hline$-5 \%$ & 0,002 & $-0,003$ & $-0,002$ & $-0,001$ & 0,040 \\
$-10 \%$ & 0,004 & $-0,003$ & $-0,005$ & 0,000 & 0,079 \\
$-20 \%$ & 0,007 & $-0,006$ & $-0,010$ & 0,004 & 0,150 \\
$-50 \%$ & 0,016 & $-0,013$ & $-0,025$ & 0,032 & 0,316 \\
\hline
\end{tabular}

Fonte: Elaboração própria.

Tabela 8 - Efeito sobre $\Omega_{L}$ e $\Omega_{Y}$

\begin{tabular}{c|cc|cc|cc|cc|cc}
\hline \multirow{2}{*}{$\mathbf{~ a r . \Omega L / Y ~}$} & \multicolumn{2}{|c|}{$\boldsymbol{\varepsilon R}$} & \multicolumn{2}{c|}{$\mathbf{R a}$} & \multicolumn{2}{c|}{$\mathbf{\varepsilon K b}$} & \multicolumn{2}{c|}{$\boldsymbol{\varepsilon Z}$} & \multicolumn{2}{c}{$\mathbf{\varepsilon h}$} \\
\cline { 2 - 11 } & $\mathbf{\Omega L}$ & $\mathbf{\Omega Y}$ & $\mathbf{\Omega L}$ & $\mathbf{\Omega Y}$ & $\mathbf{\Omega L}$ & $\mathbf{\Omega Y}$ & $\mathbf{\Omega L}$ & $\mathbf{\Omega Y}$ & $\mathbf{\Omega L}$ & $\mathbf{\Omega Y}$ \\
\hline$-5 \%$ & $-0,016$ & 0,000 & 0,024 & 0,012 & $-0,050$ & $-0,048$ & $-0,312$ & 0,018 & $-0,081$ & 0,089 \\
$-10 \%$ & $-0,032$ & 0,000 & 0,054 & 0,024 & $-0,100$ & $-0,098$ & $-0,069$ & 0,035 & $-0,159$ & 0,179 \\
$-20 \%$ & $-0,066$ & $-0,002$ & 0,133 & 0,049 & $-0,201$ & $-0,200$ & 1,170 & 0,073 & $-0,313$ & 0,363 \\
$-50 \%$ & $-0,185$ & $-0,027$ & 0,456 & 0,127 & $-0,617$ & $-0,498$ & 5,114 & 0,193 & $-0,633$ & 0,920 \\
\hline
\end{tabular}

Fonte: Elaboração própria.

Com relação à volatilidade da inflação, novamente observa-se o perfil de cooperação da política macroprudencial em relação à monetária, no caso de choque no capital bancário. $\mathrm{O}$ mesmo pode ser observado, em menor intensidade, para o caso de choque tecnológico. No que se refere à medida de avaliação de política relativa ao produto, por sua vez observam-se reduções substanciais apenas no caso de choques originados no sistema financeiro. No caso de choque de política monetária, também verifica-se potencial de cooperação entre a autoridade macroprudencial e monetária, porém com menor intensidade.

A medida de avaliação referente ao volume de crédito, outra referência importante de interesse da autoridade prudencial, apresenta reduções após a implementação da política contracíclica em quase todos os choques, excetuando-se o observado após o choque tecnológico. Nesse caso específico, além de não revelar um caráter conclusivo em relação às medidas referentes ao mercado de crédito, a política macroprudencial apresenta um papel conflitante aos objetivos da autoridade monetária, por aumentar a medida de avaliação referente ao produto, como já mencionado anteriormente. No caso de choque nas preferências do consumidor, no entanto, a redução é verificada apenas para menores sensibilidades da política prudencial. A partir de determinado ponto, uma intensificação da ação da autoridade prudencial tem o efeito de aumentar a variabilidade do volume de crédito em torno do equilíbrio. 
As Tabelas 9 e 10 apresentam os resultados para o caso em que a política macroprudencial reage a variações no volume de crédito total da economia. De maneira geral, na comparação entre os diferentes conceitos de ciclo econômico utilizados nas simulações apresentas, observa-se que sua definição não é tão relevante em caso de choque no capital bancário, uma vez que a política macroprudencial promove variações bastante semelhantes nas medidas de avaliação de políticas referentes às diversas variáveis.

Tabela 9 - Efeito sobre $\Omega_{\pi}$

\begin{tabular}{c|ccccc}
\hline Var. $\Omega_{L}$ & $\varepsilon^{R}$ & $\varepsilon^{a}$ & $\varepsilon^{K b}$ & $\varepsilon^{z}$ & $\varepsilon^{h}$ \\
\hline$-5 \%$ & 0,001 & 0,001 & $-0,001$ & 0,000 & 0,022 \\
$-10 \%$ & 0,002 & 0,002 & $-0,002$ & 0,002 & 0,045 \\
$-20 \%$ & 0,002 & 0,003 & $-0,003$ & 0,002 & 0,084 \\
$-50 \%$ & 0,002 & 0,009 & $-0,004$ & 0,006 & 0,179 \\
\hline
\end{tabular}

Fonte: Elaboração própria. 


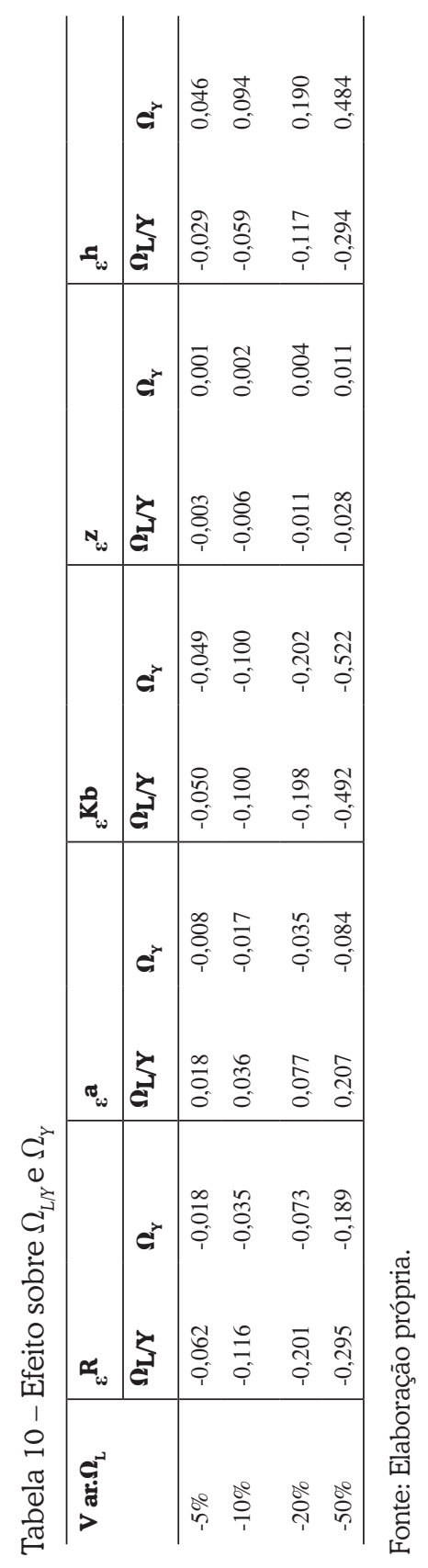

Análise Econômica, Porto Alegre, v. 39, n. 79, p. 187-224, jun. 2021. 


\section{Considerações Finais}

Este trabalho traz contribuições que buscam esclarecer os efeitos do requerimento de capital contracíclico para o alcance dos objetivos perseguidos pela autoridade prudencial e, ainda, para a coordenação com os objetivos da autoridade monetária. O modelo utilizado neste estudo introduz fricções financeiras e outros fatores que permitem avaliar o papel da oferta de crédito sobre as flutuações econômicas em um arcabouço DSGE com rigidez nominal à la Rotemberg (1982). Uma das inovações deste trabalho consiste na implementação de um índice de liquidez de curto prazo com a finalidade de replicar a incorporação do Liquidity coverage ratio (LCR) introduzido por Basileia III e, também no caso brasileiro, os requerimentos compulsórios exigidos sobre diferentes tipos de depósitos.

Avalia-se a dinâmica do modelo após a incorporação de uma política macroprudencial contracíclica e sua efetividade em termos de contribuição para os objetivos da autoridade prudencial e monetária, no caso específico do instrumento representado pelo requerimento de capital contracíclico. Em geral, observa-se a capacidade da política macroprudencial na redução da volatilidade do ciclo econômico para os diferentes choques considerados. Os resultados sugerem uma maior adequação para a utilização do instrumento de política macroprudencial contracíclico no caso da economia experimentar choques que se originam no próprio sistema financeiro e choques de política monetária. No caso dos choques de oferta e de demanda, a utilização do instrumento prudencial revelou um papel conflitante aos objetivos da autoridade monetária e um resultado não conclusivo a respeito dos benefícios sobre a estabilidade financeira.

$\mathrm{Na}$ comparação entre diferentes conceitos de ciclo econômico, percebe-se que uma maior cooperação da autoridade prudencial em relação aos objetivos da política monetária é proporcionada quando se utiliza a relação entre crédito e produto como referência para o acompanhamento do ciclo econômico em comparação com o crescimento do volume total de crédito.

\section{Referências}

ANGELINI, P.; ENRIA, A.; NERI, S.; PANETTA, F.; QUAGLIARIRELLO, M. Pro-Cyclicality of Capital Regulation: Is it a Problem? How to Fix it? Banca D'Italia Occasional Paper, n. 74, 2010 .

ANGELINI, P.; NERI, S.; PANETTA, F. Monetary and macroprudential policies. Banca D'Italia Working Paper, n. 801, 2011.

ANGELONI, I.; FAIA, E. A tale of two policies: prudential regulation and monetary policy with fragile banks. Kiel Working Papers, n. 1569, 2009. 
BANK FOR INTERNATIONAL SETTLEMENTS. Guidance for national authorities operating the countercyclical capital buffer. 2010. Disponível em: http://www.bis.org/publ/bcbs187.htm. Acesso em 20 jan. 2018.

BASEL COMMITTEE ON BANKING SUPERVISION. Basel III: International framework for liquidity risk measurement, standards and monitoring. 2010. Disponível em: http://www.bis. org/publ/bcbs188.htm. Acesso em 20 jan. 2018.

BASEL COMMITTEE ON BANKING SUPERVISION. Basel III: A global regulatory framework for more resilient banks and banking systems - revised version June 2011. 2011. Disponível em: http://www.bis.org/publ/bcbs189.htm. Acesso em 20 jan. 2018.

BASEL COMMITTEE ON BANKING SUPERVISION. Models and tools for macroprudential analysis. BCBS Working Paper, n. 21, 2012.

BEAU, D.; CLERC, L.; MOJON, B. Macro-prudential policy and the conduct of monetary policy. Banque de France Working Paper, n. 390, 2011.

BERNANKE, B. S.; GERTLER, M.; GILCHRIST, S. The financial accelerator in a quantitative business cycle framework. In: TAYLOR, J. B.; WOODFORD, M. (org.). Handbook of Macroeconomics. Amsterdam: Elsevier, 1999. v. 1. p. 1341-1393.

BLANCHARD, O. J.; KIYOTAKI, N. Monopolistic competition and the effects of aggregate demand. American Economic Review, v. 77, n. 4, p. 647-66, 1987.

BORIO, C.; FURFINE, C.; LOWE, P. Procyclicality of the financial system and financial stability: Issues and policy options. BIS Papers, n. 1, 2001.

BRANDI, V. R. Avaliação de políticas macroprudenciais em um modelo novo Keynesiano com Intermediação financeira. 2013. Tese (Doutorado em Economia) - Departamento de Economia, Universidade de Brasília, Brasília, 2013.

BRANDI, V. R.; DE ANDRADE, J. P. Avaliação de políticas macroprudenciais em um modelo com fricções financeiras estimado para a economia brasileira. Central Bank of Brazil Working Paper Series, n. 491, 2018.

BROOKS, S. P.; GELMAN, A. General methods for monitoring convergence of iterative simulations. Journal of Computational and Graphical Statistics, v. 7, n. 4, p. 434-455, 1998.

CANOVA, F. Methods for Applied Macroeconomic Research. Princeton: Princeton University Press, 2007.

CARVALHO, F. A.; CASTRO, M. R. Brazilian perspective on macroprudential and monetary policy interaction. Central Bank of Brazil Working Papers Series, n. 405, 2016.

CARVALHO, F. A.; CASTRO, M. R. Macroprudential policy transmission and interaction with fiscal and monetary policy in an emerging economy: A DSGE model for Brazil. Macroeconomics and finance in emerging market economies. Central Bank of Brazil Working Papers Series, n. 453, 2017. 
CASTRO, M. R.; GOUVEA, S. N.; MINELLA, A.; SANTOS, R. C.; SOBRINHO, N. F. S. SAMBA: Stochastic analytical model with a Bayesian approach. Central Bank of Brazil Working Paper Series, n. 239, 2011.

DIXIT, A. K.; STIGLITZ, J. E. Monopolistic competition and optimum product diversity. The American Economic Review, v. 67, n. 3, p. 297-308, 1977.

DREHMANN, M.; BORIO, C.; GAMBACORTA, L.; JIMENEZ, G.; TRUCHARTE, C. Countercyclical capital buffers: Exploring options. BIS Working Papers, n. 317, 2010.

GERALI, A.; NERI, S.; SESSA, L.; SIGNORETTI, F. M. Credit and banking in a DSGE model of the euro area. Journal of Money, Credit and Banking, v. 42, n. 1, p. 107-141, 2010.

GERTLER, M.; KARADI, P. A model of unconventional monetary policy. Journal of Monetary Economics, v. 58, n. 1, p. 17-34, 2011.

GOMES, V.; PESSOA, S. d. A.; VELOSO, F. A. Evolução da produtividade total dos fatores na economia brasileira: Uma análise comparativa. Pesquisa e Planejamento Econômico, v. 33, n. 3, p. 389-434, 2003.

HODRICK, R. J.; PRESCOTT, E. C. Postwar U.S. business cycles: an empirical investigation. Journal of Money, Credit and Banking, v. 29, n. 1, p. 1-16, 1997.

JOKIPII, T.; MILNE, A. Bank capital buffer and risk adjustment decisions. Journal of Financial Stability, v. 7, n. 3, p. 165-178, 2011.

KANNAN, P.; RABANAL, P.; SCOTT, A. M. Monetary and macroprudential policy rules in a model with house price booms. IMF Working Paper, n. 09/251, 2009.

KIYOTAKI, N.; MOORE, J. Credit cycles. Journal of Political Economy, v. 105, n. 2, p. 211-248, 1997.

LOWE, P. Credit risk measurement and procyclicality. BIS Working Papers, n. 116, 2002.

$\mathrm{MEH}, \mathrm{C}$. A.; MORAN, K. The role of bank capital in the propagation of shocks. Journal of Economic Dynamics and Control, v. 34, n. 3, p. 555-576, 2010.

PEURA, S.; KEPPO, J. Optimal bank capital with costly recapitalization. Journal of Business, V. 79, p. 2163-2201, 2006.

QUINT, D.; RABANAL, P. Monetary and macroprudential policy in an estimated DSGE model of the euro area. International Journal of Central Banking, v. 10, n. 2, 2014.

PINHEIRO, F., SAVÓIA, J.; SECURATO, J. Basileia III: Impacto para os bancos no Brasil. Revista Contabilidade 8 Finanças, v. 26, n. 69, p. 345-361, 2015.

RESENDE, C. d.; DIB, A.; PEREVALOV, N. The macroeconomic implications of changes in bank capital and liquidity requirements in Canada: Insights from the BoC-GEM-FIN. Bank of Canada, Working Papers Series, n. 16, 2010. 
ROTEMBERG, J.; WOODFORD, M. An optimization-based econometric framework for the evaluation of monetary policy. NBER Working Paper, n. 233, 1997.

ROTEMBERG, J. J. Monopolistic price adjustment and aggregate output. The Review of Economic Studies, v. 49, n. 4, p. 517-531, 1982.

SACHSIDA, A.; JUNIOR, R. d. G. E.; GOMES, V. Business cycle fluctuations in Brazil. Revista Brasileira de Economia, v. 56, n. 2, p. 269-308, 2002.

SUH, H. Evaluating macroprudencial policy with financial frictions DSGE models. 2011. Disponível em: http://citeseerx.ist.psu.edu/viewdoc/download?doi=10.1.1.463.9119Eुrep=rep $1 \mathcal{E}$ type $=$ pdf.

VANHOOSE, D. Theories of bank behavior under capital regulation. Journal of Banking $\mathcal{E}$ Finance, v. 31, n. 12, p. 3680-3697, 2007.

WOODFORD, M. Inflation stabilization and welfare. The B. E. Journal of Macroeconomics, v. 2, n. 1, 2002.

\section{Apêndice A - Efeitos da Política Macroprudencial (Crédito/Produto)}

Tabela 11 - Efeito da política macroprudencial: choque de política monetária

\begin{tabular}{|c|c|c|c|c|c|c|c|c|c|c|}
\hline$\chi_{v}$ & $\boldsymbol{\Omega}_{Y}$ & $\mathbf{\Omega}_{\pi}$ & $\mathbf{\Omega} \Delta r$ & $\mathbf{\Omega}_{L / Y}$ & $\boldsymbol{\Omega}_{L}$ & $\mathbf{\Omega} K b$ & $\mathbf{\Omega}_{s p r}$ & $\mathbf{\Omega}_{\Delta \mathbf{v}}$ & $\underset{\mathbf{t}}{\operatorname{Min}} \mathbf{v}^{b}$ & $\underset{\mathbf{t}}{\text { Máx }} \mathbf{v}^{b}$ \\
\hline 0 & 0,000 & 0,000 & 0,000 & 0,000 & 0,000 & 0,000 & 0,000 & - & 0,170 & 0,170 \\
\hline 1 & 0,000 & 0,001 & 0,000 & $-0,032$ & $-0,010$ & $-0,060$ & 0,063 & - & 0,169 & 0,170 \\
\hline 2 & 0,000 & 0,002 & 0,001 & $-0,061$ & $-0,019$ & $-0,108$ & 0,244 & - & 0,168 & 0,171 \\
\hline 3 & 0,000 & 0,003 & 0,001 & $-0,087$ & $-0,028$ & $-0,147$ & 0,476 & - & 0,168 & 0,171 \\
\hline 4 & 0,000 & 0,004 & 0,001 & $-0,111$ & $-0,036$ & $-0,178$ & 0,722 & - & 0,167 & 0,171 \\
\hline 5 & $-0,000$ & 0,005 & 0,001 & $-0,133$ & $-0,043$ & $-0,201$ & 0,967 & - & 0,166 & 0,172 \\
\hline 10 & $-0,003$ & 0,008 & 0,002 & $-0,223$ & $-0,074$ & $-0,244$ & 2,038 & - & 0,164 & 0,173 \\
\hline 15 & $-0,006$ & 0,010 & 0,003 & $-0,289$ & $-0,098$ & $-0,217$ & 2,857 & - & 0,162 & 0,173 \\
\hline 20 & $-0,010$ & 0,012 & 0,003 & $-0,341$ & $-0,118$ & $-0,163$ & 3,495 & - & 0,160 & 0,173 \\
\hline 25 & $-0,014$ & 0,013 & 0,004 & $-0,383$ & $-0,135$ & $-0,100$ & 4,007 & - & 0,159 & 0,173 \\
\hline 30 & $-0,017$ & 0,014 & 0,004 & $-0,418$ & $-0,149$ & $-0,036$ & 4,429 & - & 0,157 & 0,174 \\
\hline 50 & $-0,029$ & 0,016 & 0,005 & $-0,518$ & $-0,193$ & 0,192 & 5,580 & - & 0,154 & 0,174 \\
\hline 75 & $-0,040$ & 0,017 & 0,006 & $-0,595$ & $-0,227$ & 0,404 & 6,414 & - & 0,152 & 0,174 \\
\hline 100 & $-0,047$ & 0,018 & 0,007 & $-0,646$ & $-0,249$ & 0,559 & 6,945 & - & 0,149 & 0,174 \\
\hline
\end{tabular}

Fonte: Elaboração própria. 
Tabela 12 - Efeito da política macroprudencial: choque tecnológico

\begin{tabular}{|c|c|c|c|c|c|c|c|c|c|c|}
\hline$\chi_{v}$ & $\mathbf{\Omega}_{\mathbf{Y}}$ & $\mathbf{\Omega}_{\pi}$ & $\mathbf{\Omega} \Delta \mathbf{r}$ & $\mathbf{\Omega}_{\mathbf{L} / \mathbf{Y}}$ & $\mathbf{\Omega}_{\mathbf{L}}$ & $\mathbf{\Omega K b}$ & $\mathbf{\Omega}_{\text {spr }}$ & $\mathbf{\Omega} \Delta \mathbf{v}$ & $\underset{t}{\operatorname{Min} v^{b}}$ & $\begin{array}{c}\text { Máx } v^{b} \\
t\end{array}$ \\
\hline 0 & 0,000 & 0,000 & 0,000 & 0,000 & 0,000 & 0,000 & 0,000 & - & 0,170 & 0,170 \\
\hline 1 & 0,008 & $-0,001$ & $-0,001$ & $-0,032$ & 0,014 & 0,138 & 0,108 & - & 0,169 & 0,171 \\
\hline 2 & 0,015 & $-0,002$ & $-0,002$ & $-0,062$ & 0,030 & 0,275 & 0,280 & - & 0,168 & 0,171 \\
\hline 3 & 0,021 & $-0,003$ & $-0,003$ & $-0,089$ & 0,047 & 0,410 & 0,479 & - & 0,167 & 0,172 \\
\hline 4 & 0,028 & $-0,003$ & $-0,004$ & $-0,115$ & 0,064 & 0,539 & 0,686 & - & 0,166 & 0,172 \\
\hline 5 & 0,034 & $-0,004$ & $-0,005$ & $-0,140$ & 0,082 & 0,662 & 0,891 & - & 0,165 & 0,173 \\
\hline 10 & 0,060 & $-0,007$ & $-0,008$ & $-0,243$ & 0,170 & 1,193 & 1,798 & - & 0,162 & 0,175 \\
\hline 15 & 0,080 & $-0,009$ & $-0,010$ & $-0,322$ & 0,250 & 1,605 & 2,501 & - & 0,160 & 0,176 \\
\hline 20 & 0,097 & $-0,010$ & $-0,012$ & $-0,386$ & 0,319 & 1,932 & 3,051 & - & 0,158 & 0,177 \\
\hline 25 & 0,111 & $-0,012$ & $-0,013$ & $-0,438$ & 0,379 & 2,198 & 3,492 & - & 0,157 & 0,178 \\
\hline 30 & 0,122 & $-0,013$ & $-0,014$ & $-0,481$ & 0,432 & 2,417 & 3,853 & - & 0,156 & 0,178 \\
\hline 50 & 0,155 & $-0,015$ & $-0,017$ & $-0,602$ & 0,584 & 3,012 & 4,816 & - & 0,153 & 0,179 \\
\hline 75 & 0,179 & $-0,017$ & $-0,019$ & $-0,690$ & 0,699 & 3,430 & 5,482 & - & 0,151 & 0,180 \\
\hline 100 & 0,194 & $-0,018$ & $-0,020$ & $-0,744$ & 0,772 & 3,686 & 5,883 & - & 0,149 & 0,180 \\
\hline
\end{tabular}

Fonte: Elaboração própria.

Tabela 13 - Efeito da política macroprudencial: choque no capital bancário

\begin{tabular}{|c|c|c|c|c|c|c|c|c|c|c|}
\hline$\chi v$ & $\mathbf{\Omega Y}$ & $\mathbf{\Omega} \pi$ & $\mathbf{\Omega} \Delta \mathbf{r}$ & $\mathbf{\Omega L} / \mathbf{Y}$ & $\mathbf{\Omega} \mathbf{L}$ & $\mathbf{\Omega K b}$ & 几spr & $\mathbf{\Omega \Delta v}$ & $\begin{array}{c}\text { Min vb } \\
\mathbf{t}\end{array}$ & $\begin{array}{c}\text { Máx vb } \\
t\end{array}$ \\
\hline 0 & 0,000 & 0,000 & 0,000 & 0,000 & 0,000 & 0,000 & 0,000 & - & 0,170 & 0,170 \\
\hline 1 & $-0,023$ & $-0,001$ & $-0,011$ & $-0,024$ & $-0,023$ & 0,011 & $-0,028$ & - & 0,170 & 0,170 \\
\hline 2 & $-0,044$ & $-0,002$ & $-0,020$ & $-0,046$ & $-0,046$ & 0,021 & $-0,055$ & - & 0,169 & 0,170 \\
\hline 3 & $-0,065$ & $-0,003$ & $-0,028$ & $-0,067$ & $-0,067$ & 0,031 & $-0,079$ & - & 0,169 & 0,170 \\
\hline 4 & $-0,085$ & $-0,004$ & $-0,035$ & $-0,087$ & $-0,087$ & 0,041 & $-0,102$ & - & 0,168 & 0,170 \\
\hline 5 & $-0,104$ & $-0,005$ & $-0,041$ & $-0,106$ & $-0,106$ & 0,050 & $-0,123$ & - & 0,168 & 0,170 \\
\hline 10 & $-0,190$ & $-0,009$ & $-0,062$ & $-0,190$ & $-0,191$ & 0,089 & $-0,212$ & - & 0,166 & 0,170 \\
\hline 15 & $-0,261$ & $-0,013$ & $-0,072$ & $-0,258$ & $-0,261$ & 0,120 & $-0,279$ & - & 0,165 & 0,171 \\
\hline 20 & $-0,322$ & $-0,017$ & $-0,077$ & $-0,315$ & $-0,319$ & 0,146 & $-0,332$ & - & 0,165 & 0,171 \\
\hline 25 & $-0,374$ & $-0,019$ & $-0,078$ & $-0,364$ & $-0,369$ & 0,168 & $-0,374$ & - & 0,164 & 0,171 \\
\hline 30 & $-0,419$ & $-0,021$ & $-0,078$ & $-0,406$ & $-0,413$ & 0,186 & $-0,409$ & $\therefore$ & 0,163 & 0,171 \\
\hline 50 & $-0,552$ & $-0,026$ & $-0,073$ & $-0,529$ & $-0,541$ & 0,239 & $-0,503$ & - & 0,162 & 0,171 \\
\hline 75 & $-0,653$ & $-0,028$ & $-0,064$ & $-0,625$ & $-0,641$ & 0,279 & $-0,568$ & - & 0,161 & 0,171 \\
\hline 100 & $-0,717$ & $-0,029$ & $-0,056$ & $-0,689$ & $-0,707$ & 0,305 & $-0,605$ & - & 0,161 & 0,171 \\
\hline
\end{tabular}

Fonte: Elaboração própria. 
Tabela 14 - Efeito da política macroprudencial:choque nas preferências do consumidor

\begin{tabular}{|c|c|c|c|c|c|c|c|c|c|c|}
\hline$\chi v$ & $\mathbf{\Omega Y}$ & $\mathbf{\Omega} \pi$ & $\mathbf{\Omega} \Delta \mathbf{r}$ & $\mathbf{\Omega L} / \mathbf{Y}$ & $\mathbf{\Omega L}$ & $\mathbf{\Omega K b}$ & $\mathbf{\Omega s p r}$ & $\mathbf{\Omega} \Delta v$ & $\underset{t}{\text { Mín vb }}$ & $\underset{t}{\text { Máx vb }}$ \\
\hline 0 & 0,000 & 0,000 & 0,000 & 0,000 & 0,000 & 0,000 & 0,000 & - & 0,170 & 0,170 \\
\hline 1 & 0,012 & $-0,001$ & 0,007 & $-0,034$ & $-0,297$ & 0,217 & $-0,608$ & - & 0,169 & 0,170 \\
\hline 2 & 0,023 & $-0,001$ & 0,014 & $-0,066$ & $-0,327$ & 0,571 & 0,002 & - & 0,168 & 0,170 \\
\hline 3 & 0,033 & $-0,000$ & 0,020 & $-0,095$ & $-0,123$ & 0,961 & 0,772 & - & 0,168 & 0,171 \\
\hline 4 & 0,043 & 0,000 & 0,026 & $-0,122$ & 0,166 & 1,349 & 1,498 & - & 0,167 & 0,171 \\
\hline 5 & 0,053 & 0,001 & 0,032 & $-0,147$ & 0,469 & 1,722 & 2,174 & - & 0,166 & 0,171 \\
\hline 10 & 0,092 & 0,006 & 0,057 & $-0,249$ & 1,818 & 3,322 & 4,915 & - & 0,164 & 0,171 \\
\hline 15 & 0,122 & 0,013 & 0,077 & $-0,326$ & 2,843 & 4,543 & 6,911 & - & 0,162 & 0,172 \\
\hline 20 & 0,146 & 0,019 & 0,092 & $-0,386$ & 3,639 & 5,501 & 8,434 & - & 0,160 & 0,172 \\
\hline 25 & 0,166 & 0,024 & 0,105 & $-0,435$ & 4,277 & 6,274 & 9,638 & - & 0,159 & 0,172 \\
\hline 30 & 0,183 & 0,029 & 0,115 & $-0,475$ & 4,801 & 6,912 & 10,615 & - & 0,158 & 0,172 \\
\hline 50 & 0,228 & 0,044 & 0,144 & $-0,588$ & 6,217 & 8,648 & 13,207 & - & 0,156 & 0,172 \\
\hline 75 & 0,261 & 0,055 & 0,165 & $-0,670$ & 7,223 & 9,887 & 14,995 & - & 0,154 & 0,172 \\
\hline 100 & 0,282 & 0,062 & 0,177 & $-0,723$ & 7,848 & 10,658 & 16,080 & - & 0,153 & 0,172 \\
\hline
\end{tabular}

Fonte: Elaboração própria.

Tabela 15 - Efeito da política macroprudencial: choque na demanda pelo bem imobiliário

\begin{tabular}{|c|c|c|c|c|c|c|c|c|c|c|}
\hline$\chi_{v}$ & $\boldsymbol{\Omega}_{Y}$ & $\mathbf{\Omega}_{\pi}$ & $\mathbf{\Omega}_{\Delta r}$ & $\mathbf{\Omega}_{L / Y}$ & $\boldsymbol{\Omega}_{L}$ & $\mathbf{\Omega} K b$ & $\mathbf{\Omega}_{s p r}$ & $\mathbf{\Omega}_{\Delta \mathbf{v}}$ & $\underset{t}{\text { Min }^{b}}$ & $\begin{array}{c}\text { Máx } \mathbf{v}^{b} \\
\mathbf{t}\end{array}$ \\
\hline 0 & 0,000 & 0,000 & 0,000 & 0,000 & 0,000 & 0,000 & 0,000 & - & 0,170 & 0,170 \\
\hline 1 & 0,043 & 0,020 & 0,024 & $-0,024$ & $-0,039$ & 0,320 & 1,248 & - & 0,170 & 0,171 \\
\hline 2 & 0,084 & 0,038 & 0,046 & $-0,047$ & $-0,076$ & 1,713 & 3,329 & - & 0,170 & 0,171 \\
\hline 3 & 0,122 & 0,055 & 0,066 & $-0,069$ & $-0,110$ & 3,118 & 5,321 & - & 0,170 & 0,172 \\
\hline 4 & 0,159 & 0,070 & 0,085 & $-0,089$ & $-0,142$ & 4,459 & 7,188 & - & 0,169 & 0,173 \\
\hline 5 & 0,194 & 0,085 & 0,102 & $-0,108$ & $-0,172$ & 5,731 & 8,936 & - & 0,169 & 0,173 \\
\hline 10 & 0,346 & 0,144 & 0,172 & $-0,191$ & $-0,300$ & 11,162 & 16,207 & - & 0,169 & 0,175 \\
\hline 15 & 0,469 & 0,188 & 0,224 & $-0,258$ & $-0,397$ & 15,408 & 21,706 & - & 0,168 & 0,177 \\
\hline 20 & 0,571 & 0,221 & 0,264 & $-0,313$ & $-0,471$ & 18,823 & 26,027 & - & 0,168 & 0,179 \\
\hline 25 & 0,657 & 0,247 & 0,295 & $-0,359$ & $-0,527$ & 21,635 & 29,524 & - & 0,168 & 0,180 \\
\hline 30 & 0,730 & 0,268 & 0,320 & $-0,399$ & $-0,569$ & 23,993 & 32,419 & - & 0,168 & 0,181 \\
\hline 50 & 0,943 & 0,322 & 0,387 & $-0,512$ & $-0,641$ & 30,578 & 40,348 & - & 0,167 & 0,183 \\
\hline 75 & 1,107 & 0,358 & 0,434 & $-0,600$ & $-0,625$ & 35,416 & 46,061 & - & 0,167 & 0,185 \\
\hline 100 & 1,215 & 0,379 & 0,462 & $-0,657$ & $-0,584$ & 38,478 & 49,649 & - & 0,167 & 0,187 \\
\hline
\end{tabular}

Fonte: Elaboração própria. 


\section{Autor correspondente:}

Vinicius Ratton Brandi

Recebido em: 02/02/2018.

vinicius.brandi@gmail.com

Aceito em: 06/11/2019.

\section{(cc) BY}

Este é um artigo de acesso aberto distribuído sob os termos da Creative Commons

Attribution CC-BY 4.0, que permite uso irrestrito, distribuição e reprodução em

qualquer meio, desde que o trabalho original seja devidamente citado. 